C E N T E R F O R

E C O N O M I C

B E H A V I O R \&

I N E Q U A L I T Y

CEBI WORKING PAPER SERIES

Working Paper 03/19

THE WEALTH OF PARENTS: TRENDS OVER TIME IN ASSORTATIVE MATING BASED ON PARENTAL HEALTH

Sander Wagner

Diederik Boertien

Mette Gørtz

ISSN 2596-44TX

\title{
CEBI
}

Department of Economics University of Copenhagen www.cebi.ku.dk 


\title{
The Wealth of Parents:
}

\section{Trends over Time in Assortative Mating Based on Parental Wealth}

\author{
Sander Wagner ${ }^{\dagger}$ \\ Diederik Boertien \\ Mette Gørtz ${ }^{\S}$
}

June 24, 2019

\begin{abstract}
This paper presents trends in parental wealth homogamy across union cohorts formed between 1987 and 2013 in Denmark. Using high-quality register data on the wealth of parents during the year of partnering through cohabitation or marriage, we show that the correlation between partners' levels of parental wealth is considerably lower compared to estimates from earlier research on other contexts. Nonetheless, parental wealth homogamy is high at the very top of the parental wealth distribution, and individuals from wealthy families are relatively unlikely to partner individuals from families with low wealth. Even though conclusions regarding trends in parental wealth homogamy depend on methodological choices made, most specifications indicate an increase in homogamy in the 2000s as compared to the 1990s. This raises concerns about the consequences of changes in partnering behavior for wealth inequality between households and social boundaries between groups based on parental wealth and particularly between the wealthiest individuals in society and the rest of the population.
\end{abstract}

Keywords: Marriage, assortative mating, wealth

JEL: D31, J12, J60

Acknowledgements: We appreciate generous funding for Sander Wagner from Labex-Ecodec, for Mette Gørtz from the Danish National Research Foundation through its grant (DNRF-134) to CEBI, and for Diederik Boertien from the Beatriu de Pinos program of the Generalitat de Catalunya (2016-BP-00121) as well as the EQUALIZE project led by Iñaki Permanyer (ERC2014-STG-grant agreement No 637768). We also appreciate input from seminar attendants at the Crest Sociology Lab, the Center for Demographic Studies, and University of Southern Denmark. The usual disclaimer applies.

$\uparrow$ CREST/ENSAE, Université Saclay Paris. sander.wagner@ensae.fr

\$ Center for Demographic Studies, Barcelona. dboertien@ @ed.uab.es

$\S$ CEBI, Department of Economics, University of Copenhagen. mette.gortz@econ.ku.dk 


\section{Introduction}

Partnering behavior is a key determinant of various important aspects of well-being (Schwartz 2013). From an economic point of view, marriage and cohabitation create the foundation for the sharing of public goods and specialization in the family, risk pooling, credit and coordination of childcare (Browning et al. 2014). It is therefore unsurprising that partnering does not happen at random, and that marital sorting is a key feature of marriage models (Becker 1973, 1991; Lam 1988). Social scientists have long documented patterns of assortative mating based on ascribed characteristics such as parental occupation and ethnicity (Kalmijn 1998; Schwartz 2013), as well as on acquired characteristics like education and earnings (Blossfeld 2009; Pencavel 1998; Rosenfeld 2008; Schwartz and Mare 2005; Schwartz, 2010). Besides the impact of partnering on individual well-being, assortative mating has been of interest for research on social stratification as it potentially impacts the distribution of resources across households and shapes boundaries between social groups (Kremer 1997; Schwartz 2010; 2013).

In this article, we study partner selection based on parental wealth, a characteristic that is of particular interest for social stratification research for several reasons. First, a substantial amount of own wealth is the result of inheritance of parental wealth; a characteristic that is latent, but often not measured at the moment of couple formation, since parents are still alive. Kopczuk and Lupton's (2007) review of the literature estimates bequests to make up around $35-45 \%$ of overall wealth of an individual in the United States. High levels of parental wealth homogamy may therefore contribute to wealth inequality between households. Second, wealth homogamy can shed light on important questions about intergenerational mobility processes. Examples of such questions are: To what extent is it possible to marry out of poverty? Do rich families reproduce their accumulated wealth across generations through partnering choices? How many generations does it take until the current distribution of wealth does not affect life chances anymore?

To date, few studies have examined the extent to which partners match on parental wealth. To the best of our knowledge, the current literature is limited to a study of parental wealth homogamy using data from 1988 for the United States (Charles et al. 2013), and an article on the concentration of inheritances within couples in France during the 1990s and 2000s (Fremeaux 2014). Both studies indicate that people do tend to select partners who are similar to themselves in terms of parental wealth. Using the 1988 wave of the Panel Study of Income 
Dynamics, Charles et al. (2013) estimated the correlation between parents' (positive) wealth to be about .4 after controlling for age and race.

In this study, we contribute to this emerging literature by studying parental wealth homogamy in Denmark. We use registry data for marriage and union cohorts formed between 1986 and 2013. A major contribution of our work is that we are, to our knowledge, the first to study trends in parental wealth homogamy over time. Earlier research is limited to a finding by Fremeaux (2014) showing that sorting on inheritances remained stable from 1992 to 2010 in France.

A main focus of our study is on different ways of empirically estimating and interpreting trends in parental wealth homogamy. Studying parental wealth homogamy is fraught with conceptual and methodological challenges, which include the measurement of parental wealth, changes in the composition of wealth across time, parental partnering dynamics and selective mortality. Compared to earlier research, we believe that our study offers improvements to dealing with these challenges. First, we study cohorts in the year of union formation, instead of looking at a cross-section of unions with varying union durations. Second, we use intergenerationally linked registry data for the whole population with precise measurement of parental wealth. Earlier studies used data on inheritances (Fremeaux 2014) or survey data based on respondents' estimates of their own and spouses' living parents' wealth (Charles et al. 2013). Third, we are able to (partly) recover information on parental wealth for individuals whose parents passed away before union formation. Fourth, parental wealth is measured at the individual rather than the household level in our data, allowing for a more straightforward inclusion of re-married parents. Finally, the longitudinal data structure allows us to verify the sensitivity of estimates to the time at which parental wealth is measured.

Before turning to these empirical issues, we provide a brief theoretical discussion as to why partners might select each other based on parental wealth, and why the importance of such mechanisms might change over time.

\section{Parental Wealth Homogamy: Mechanisms}

According to Kalmijn (1998), partnering homogamy is influenced by i) preferences of individuals for partners with certain characteristics, ii) the interference of third parties in the selection process, and iii) constraints on the chances of meeting people due to structural factors. 
There are good reasons to expect people to have preferences for partners with high parental wealth. Parental wealth can have a positive influence on the attractiveness of potential partners not only directly, as parental wealth is likely to be transferred to children (Boserup et al. 2018; Killewald et al. 2017; Schneider, 2011; Spilerman 2000), but also indirectly, as wealth allows parents to invest more in their children's human capital and facilitates access to better health and education (Eads and Tach, 2016; Killewald et al. 2017; Pfeffer 2011; 2018; Pfeffer and Schoeni, 2016; Rauscher 2016; Thompson and Conley 2016).

Beyond its effect on the attractiveness of potential partners, family wealth is bound to also influence tastes, preferences and lifestyles that individuals develop and might therefore lead to higher degrees of partnering among individuals with similar parental wealth, even without an explicit preference for a partner with high parental wealth (Kalmijn 1991).

As regards the influence of third parties on partner choices, parents are the most obvious party interested in the partnering process of their children (Kalmijn 1998; Rosenfeld and Kim 2005). Parents are bound to be interested in the parental wealth of their child's partner for similar reasons as the ones outlined above. Parents might have direct preferences for seeing their children find a partner from a rich family, as this means that their child can potentially access partners' parental wealth at some point, as well as indirect reasons, as parents might have class and lifestyle preferences extending to their child's partner.

The last group of factors influencing partnering consists of opportunities for meeting individuals with similar characteristics. Even without any preferences for parental wealth and its related characteristics, homogamy might simply arise due to the fact that individuals being born into wealthier or poorer families are more likely to be in contact with each other. The reasons for this lie in the effects of parental wealth on residential, educational and occupational segregation, lifestyle habits and social networks. That there is residential segregation due to parental wealth during childhood and potentially young adulthood is obvious. But even when offspring leave the parental home, parental wealth can enable offspring to rent or buy residences in richer areas than individuals without parental wealth (Charles and Hurst 2002). Because family wealth also influences the likelihood to go to certain schools and universities, social networks built during the educational trajectory will be relatively homogenous in terms of parental wealth as well (Blossfeld 2009). 


\section{Changes over Time}

Theories about modernisation generally hypothesize that homogamy based on ascribed characteristics (such as parental wealth) declines over time, whereas acquired characteristics gain in importance (Kalmijn 1991). Educational expansion, the increasing length of educational careers and increasing geographical mobility are expected to have increased the importance of own socioeconomic standing, social networks, lifestyles and preferences relative to parental characteristics (Blossfeld 2009; Rosenfeld and Kim 2005; Schwartz 2013). Declining levels of homogamy have been observed for ascribed characteristics such as parental occupation (Henz and Mills 2018; Kalmijn 1991; Rosenfeld 2008). One might therefore expect this pattern to extend to parental wealth homogamy too.

A reason why parental wealth might, on the other hand, have become more important in partner searches is that wealth inequality has increased considerably in many Western countries (Piketty 2014), including Denmark (Jakobsen et al. 2018). This higher inequality might have made the benefits related to wealth stronger and more salient. Studies have found some support for increased homogamy (Torche 2010; Monaghan 2015) and longer partner searches (Gould and Passerman 2003) in contexts of high income inequality. Further, increased wealth inequality can lead to more pronounced differences in tastes and behaviours and augment residential segregation, thus reducing opportunities of individuals from different family backgrounds to meet (Smith et al. 2014).

\section{Our Study: Parental Wealth Homogamy in Denmark}

In this paper we study trends in parental wealth homogamy in Denmark from 1987 to 2013. Not all mechanisms discussed above may apply to Denmark to the same extent. On the one hand, even though income inequality is relatively low in Denmark, wealth inequality appears to be surprisingly high in comparison to other Western countries (Balestra and Tonkin 2018), potentially enhancing the role of wealth in the partnering process. As wealth inequality increased slightly over the last decades (Jakobsen et al. 2018) such considerations may have increased in importance over time. On the other hand, the intergenerational transmission of wealth in Denmark is lower compared to the United States (Boserup et al. 2013), which could therefore reduce the preference for partners with high parental wealth. Even though the greatest expansion of tertiary education in Denmark took place before the 1980s, rates of tertiary 
education attendance have risen steadily between 1980 and 2010 (Barro and Lee 2015). Educational expansion might therefore have increased the possibilities to date across parental wealth boundaries, as tertiary education became less restricted to a select group of individuals.

\section{Data and Method}

Our data source is the unique Danish register data, which is available for researchers in anonymized form through Statistics Denmark. This comprehensive data on the complete population residing in Denmark in the years 1986-2013 come from several public administration registers compiled by Statistics Denmark based on unique personal identification numbers at birth. Tax registries in Denmark collect data on the value of individuals' assets and liabilities, mostly provided by third parties (e.g. assessments of housing values are made by the tax authorities). Denmark taxed wealth until 1996, but the collection of wealth data continued with some slight modifications after its abolishment (Jakobsen et al., 2018). Information from the population registers allows us to link parents to children.

Our sample includes all different-sex co-residing unions formed during the period 1987-2013. Union formation is determined based on the entry into co-residence of two individuals who were either married, had a registered partnership, cohabited with children or cohabited without children (Drefahl 2012). ${ }^{1}$ A requirement for inclusion in our sample is the presence of parental identification numbers of the father and the mother of both individuals, allowing us to link parents to children in the registry data. Such parental identification numbers have been systematically recorded for all individuals born after 1960, but are incomplete for earlier birth cohorts (Boserup et al. 2013). ${ }^{2}$ We therefore restrict our sample to couples where both partners are between 18 and 34 years old at the time of union formation. In robustness checks we expand this age range to 40, but restrict the period covered by our analysis to $1992-2013 .{ }^{3}$ Finally, we exclude couples where one of the parents was not present in the registry data after 1980 (the

\footnotetext{
${ }^{1}$ This latter category only includes households of two unrelated adults who had an age difference of less than 15 years and who were not related by family ties. A small minority of cases might therefore not regard romantically involved individuals. In robustness checks we exclude unions that lasted less than 3 years to filter out such possible arrangements as much as possible; see figure B2 in the Online Appendix, results do not change.

${ }^{2}$ Figure A1 in the Online Appendix shows the distribution of cases that had no parental identification numbers by age and year. There we also discuss various robustness checks that address concerns about whether a changing age composition of the sample affected results (e.g. including sample weights to compensate for possible unequal probabilities of inclusion by birth year)

${ }^{3}$ Online Appendix B1; Results are robust.
} 
first year we have information on wealth). Parents are not present in the registry data if they have passed away or live abroad.

\section{Parental Wealth}

Wealth is measured as total assets (financial assets and housing) minus debts as retrieved by Statistics Denmark from data collected by the Danish Tax Agency. Wealth comprises a large variety of sources including the value of properties such as houses, boats and cars; bonds; stocks; cash in banks; value of businesses; loans; and mortgages. One component not included in the measurement of wealth is accumulated pension wealth. Most information is provided by third parties such as banks, financial institutions and other governmental bodies. The value of properties is assessed by tax authorities based on detailed information on their characteristics (Boserup et al. 2013). ${ }^{4}$ During the observation period, there are changes in how some sources of wealth are reported, mainly due to the removal of the wealth tax in 1996. Specifically, the value of stocks was self-reported until 1996 but provided by financial institutions ever since, some assets that were self-reported until 1996 were not recorded anymore after that (including cars, boats, caravans) and the registration of company values changed several times until 1997 (Jakobsen et al. 2018). Boserup and colleagues (2013) exploited an overlap in both ways of measuring wealth to show how the measurement of wealth from 1997 onward was well approximated by the measurement of wealth up to that point.

Wealth is measured at the individual level, and we therefore sum the wealth of parents regardless of parents' marital status. Parental wealth is measured separately for male and female partners. Following earlier research (Solon 2004), we average parental wealth across three years. ${ }^{5}$ So far, our theoretical discussion, as well as existing research on parental wealth homogamy (Charles et al. 2013; Fremeaux 2014), has treated parental wealth as a stable characteristic of individuals. In reality, however, parental wealth changes over time. This poses conceptual as well as methodological challenges on when and how to best measure parental wealth. Wealth depends on time-varying processes such as housing prices, stock market fluctuations, individual earnings and consumption patterns, as well as windfalls or unlucky

\footnotetext{
${ }^{4}$ Tax assessed housing values have historically not always reflected fully the market values at the time. Following Boserup et al. (2013) and Browning et al. (2013), we adjust tax assessed housing values with a factor that reflects the average relationship between market values of traded houses and average tax assessed values, thus arriving at an imputed estimate of the market value of housing wealth.

${ }^{5}$ All wealth and income components are deflated with a GDP deflator to the 2010 price level.
} 
events. A family's position in the wealth distribution therefore depends on the time of measurement. Our response to the question of when to measure parental wealth has been to compare measurements at different points in time.

If one considers parental wealth as an economic resource that children signal directly to future partners and which holds the potential of joint future consumption, parents' wealth at the time of union formation will be the important factor for partnering. We therefore introduce parental wealth in the year of union formation as our first and primary measure. To construct the measure $p w 1_{i}$ capturing parental wealth of individual $i$ in the year of union formation $y=u$ let $R_{y=u, \operatorname{sex}(i)}$ be an operator assigning the percentile rank based on the distribution of parental wealth of all individuals that formed a union in the same year $y=u$ and that are of the same $\operatorname{sex}(i)$ as individual $i$, which means we separately look at the parental wealth distribution of all daughters and of all sons that formed a union in year $y$. Parental wealth $w_{p}=w_{f}+w_{m}$ is calculated as being the sum of the wealth of fathers $w_{f}$ and mothers $w_{m} \cdot{ }^{6}$

(1) $p w 1_{i}=R_{y=u, \operatorname{sex}(i)}\left(w_{p, i, y=u}\right)$

In robustness checks, we log transform the total sum of parental wealth in the year of union formation, instead of using a rank-based measure.

A problem with measuring parental wealth at union formation is that it is highly dependent on age. Wealth is generally accumulated throughout adulthood and peaks around age 60, after which levels of wealth start declining (Killewald et al. 2017). An individual with young parents might therefore have low parental wealth at union formation, but this might be a poor predictor of parents' future wealth and hence of the volume of expected transfers and inheritances. The second measure we employ therefore indicates parental wealth in the year of union formation normalized by father's age. In this case, before calculating the rank of parental wealth within a given union cohort, parental wealth is normalized separately by father's age. As this measure reflects wealth of parents relative to peers from their specific birth cohorts, it also accounts, to some extent, for the distribution of children's age at union formation, as older individuals are likely to have older parents on average. Normalization is done by subtracting the average $\mu$ and

\footnotetext{
${ }^{6}$ In reality we calculate the percentiles on the distribution of year normalized wealth, so instead of $w_{p i, y=u}$ we calculate $\left(w_{p i, y=u}-\mu_{y=u}\left(w_{p}\right)\right) / s d_{y=u}\left(w_{p}\right)$, meaning we substract the average of parental wealth in the year of union formation and divide by its standard deviation. This results in the same distribution, except that it allows us to pull forward the wealth of deceased parents in a comparable way and integrate it into the wealth distribution of the year that their child formed a union.
} 
calculating the standard deviation sd of the wealth of all parents where the father has the same age as the father of individual $i \operatorname{age}(f)=\operatorname{age}(f i)$ and where union formation took place in year $u$.

(2) $p w 2_{i}=R_{y=u, \operatorname{sex}(i)}\left[w_{p, i}-\mu_{\text {age }(f)=\operatorname{age}(f i)}\left(w_{p}\right) / d_{\text {age }(f)=\operatorname{age}(f i)}\left(w_{p}\right)\right]$

A third and final alternative is to consider parental wealth as a socialization factor that shapes individuals' preferences and lifestyles and determines interpersonal networks while growing up. In this case, a parents' relative wealth position during childhood and adolescence is the best indicator to use. Our third measure employed, parental wealth at age 18, therefore used parental wealth from the year when respondents were aged 18, which is denoted as $w_{p, y=(y \mid a g e=18)}$. We subsequently normalized individuals' wealth by subtracting the average of parental wealth at age 18 and dividing by the standard deviation. The sample from which we calculated the mean and standard deviation were all individuals who are of the same age age = age $(i)$ and sex as $i$ and also formed a union in year $u$.

(3) $p w 3_{i}=R_{y=u, \operatorname{sex}(i)}\left[w_{p, i, y=(y \mid \operatorname{age}(i)=18)}-\mu_{\text {age=age }(i),}\left(w_{p, y=(y \mid \operatorname{age}=18)}\right) / s d_{\text {age }=\operatorname{age}(i)}\left(w_{p, y=(y \mid \operatorname{age}=18)}\right)\right]$

Due to the more strict data requirements, the sample used for this measure is smaller than the sample used with the two other wealth measures.

Besides choosing at which point in time to measure parental wealth, two other important issues complicate the measurement of parental wealth. Firstly, parents might have passed away before wealth is measured. Fremeaux (2014) tackled this issue in his study on inheritance homogamy by combining information on inheritances received with estimates of expected inheritances. Charles and colleagues (2013) did not have information on the wealth of parents who passed away. Our solution is to measure parental wealth in the last wave before union formation where both parents were still alive. ${ }^{7}$ In robustness checks, we exclude cases where a parent passed away before union formation. Our measure of parental wealth at age 18 excludes cases where parents had passed away before age 18 .

Secondly, parents might not be together anymore at the time of union formation. If parents repartner, household-based measures of wealth might complicate arriving at a comparable measure of parental wealth for individuals whose parents did and did not form new families. Charles and colleagues (2013) therefore excluded individuals with re-married parents. Danish

\footnotetext{
${ }^{7}$ Parental wealth is in these cases normalized in the year both parents were still alive and this value is subsequently used in the calculation of the parental wealth rank for each annual union cohort.
} 
registry data allow for the measurement of wealth at the individual level, enabling us to sum parents' individual wealth and to disregard the wealth of eventual new partners of the parents. In robustness checks, couples with one or more re-married parents are excluded from the analysis.

\section{Sample Description}

Table 1 provides descriptive statistics for the overall sample of 803,185 couples with full information on parental wealth in the year of union formation. Besides descriptive statistics for the sample overall, averages are presented for unions formed in 1987 and 2013 to monitor changes over time in the composition of the sample. The descriptive statistics show that men are on average older than women at union formation, and the same applies to their parents. Ages of all individuals involved have slightly increased during the observation period. Only $6 \%$ of couples were married at union formation, preventing us from performing a separate analysis on a subsample of marriages. We treat married and cohabiting couples as one group as cohabitation as an alternative to marriage is widespread in Denmark. ${ }^{8}$ Parental wealth is higher for men's parents as compared to women's parents. $25 \%$ of men's parents report negative wealth and this share increased with time from $18 \%$ in 1987 to $35 \%$ in 2013. Negative wealth can arise due to recent investments made, accumulated debts, or due to a mismatch between the value of houses as estimated by the authorities and the real market value of a property. ${ }^{9}$ We pay particular attention to cases with negative parental wealth in the analysis. Due to the precise measurement of wealth, very few couples had zero wealth (less than $0.2 \%$ of cases). Figure 1 breaks down the wealth of the male partners' parents into housing assets, financial assets, and debt. Housing assets make up most of wealth across the distribution, even though financial assets become more visible at the top of the wealth distribution. ${ }^{10}$ Figure 1

\footnotetext{
${ }^{8}$ In 2018, one in four Danish couples were cohabiting rather than married, and the same cohabitation rate applies to couples with children, according to own calculations based on data from Statistics Denmark, www.statistikbanken.dk. We run robustness checks excluding short cohabitation spells (<3 years).

${ }^{9}$ Information on tax assessed housing values should in principle reflect market values for comparable traded houses. However, as the majority of houses are not traded each year, the tax authorities' estimated market values of houses may be too low (high), which can happen because specific unobserved characteristics such as e.g. interior design (new kitchen or bathrooms) are not taken into account by valuation authorities. Thus, the higher actual market values can translate into higher mortgages as compared to the value of the house as indicated by the taxable values data.

${ }^{10}$ With financial deregulation and various reforms through the 1990s and early 2000s, house owners access to e.g. refinancing their mortgage debt implied on average an increase in debt in relation to housing values (Browning et al. 2013).
} 
also shows high levels of debt and assets at the very bottom of the distribution. Very low levels of wealth might therefore indicate recent investments made rather than an economically difficult situation (Killewald 2013).

-Table 1 about here-

Figure 2 shows trends in median and median absolute deflated wealth over time. Median and mean wealth declined very slightly until the mid-1990s, took off dramatically after that, and decreased considerably after the onset of the financial crisis. Figure 3 documents how inequality measured by the Gini coefficient in parental wealth followed an opposite pattern with increasing inequality until the early $1990 \mathrm{~s}$, a brief decline followed by stabilization and a subsequent increase in recent years. On average, the Gini coefficient in wealth over the period observed is around .7, which is in accordance with other studies of wealth inequality (Danish Economic Council, 2016; Balestra and Tonkin 2018).

-Figures 1-3 about here-

\section{Procedure}

As the main aim of our analysis is descriptive in nature, most of our analysis will concentrate on the challenges of empirically estimating trends in parental homogamy. We consider factors that can explain why parental homogamy changed to be out of the scope of the current paper, and leave such issues for future research including the role of changes in educational homogamy. We commence the analysis by describing the association between partners' parental wealth. Firstly, we document the relative frequency of couple combinations based on men's and women's parental wealth percentiles using a heatmap. Secondly, we show average male partner's parental wealth according to the female partner's parental wealth. This will give insights into whether there exists a non-linear relationship or not. After describing assortative mating patterns, we summarize the strength of assortative mating using correlations and document how the correlation in partners' parental wealth has changed over time. We subsequently answer the question to what extent the time at which parental wealth is measured matters for conclusions. Finally, we test the robustness of these trends to various other choices regarding the measures used and sample restrictions applied. A main goal is to make our results as comparable as possible to earlier results on the United States (Charles et al. 2013) in order to compare levels of parental homogamy across Denmark and the US. 


\section{Results}

Figure 4 provides an indication of how frequently men and women with given levels of parental wealth form a union together. The graph depicts the joint distribution of parental wealth by percentiles, showing males on the $\mathrm{x}$-axis and females on the $\mathrm{y}$-axis. For each percentile in the male ranking, a random distribution of marriages would imply that exactly 1 percent of these would be to a woman in each of the 100 percentiles in the female parental wealth distribution. We estimated how large the actual proportions of couples found in each $100 * 100$ cell were in the joint partnering distribution. A value of 1 in Figure 4 thus indicates an observed frequency that would be expected if partnering were to be at random, a value of 2 indicates a relative frequency that is twice greater than expected. Dark areas indicate relatively common combinations (up to 2.5 times the probability of the random match), whereas lighter areas are relatively less common (less than the probability of the random match).

-Figure 4 about here-

The graph shows high relative frequencies along the diagonal, indicating positive assortative mating, and a concentration of couples in the top-right corner, indicating couples where both his and her parents are among the wealthiest parents of their union cohorts. At the same time, the clustering of lighter areas in the top-left and bottom-right corners shows that individuals from the wealthiest families are relatively unlikely to partner with individuals from families that are roughly in the bottom $30 \%$ of the wealth distributions. In other words, individuals from the wealthiest families are the most likely to form homogenous partnerships, and they especially avoid partnering with individuals from families with low levels of wealth.

One peculiarity is formed by the relatively dark areas observed along the $\mathrm{x}$ - and y-axes, which indicate the likelihood to partner with an individual from the very bottom of the parental wealth distribution. These individuals have parents who have the largest amounts of negative wealth. This could reflect that debt can also indicate access to credit rather than a severely disadvantaged economic situation (Killewald 2013). Given that a large portion of debt is mortgage debt or other debt that requires collateral, these might be parents who just made an investment in a business or bought a new house. Moreover, as previously mentioned, negative wealth might also reflect that housing values in the data sometimes underestimate the true market values. 
To further describe patterns of parental wealth homogamy, the left panel of Figure 5 shows the average parental wealth percentile of male partners according to female partners' parental wealth percentile for three groups of union cohorts. In general, the more parental wealth female partners have, the higher the parental wealth of their male partner. The right panel shows a smoothened line indicating the general pattern for three different cohorts. The tendency for partners' parental wealth rank to increase with own parental wealth appears to be stronger for more recent union cohorts, indicating a rise in homogamy. The largest differences in average parental wealth observed amount to a difference of 12 percentiles in the average parental wealth rank of male partners. An exception to the general positive association in parental wealth is observed for women with very low parental wealth whose partners' average parental wealth is not as low as one might expect. As mentioned, this is likely due to some values of negative wealth indicating access to credit rather than a difficult economic situation.

-Figure 5 about here-

\section{Correlation in ranks}

In the following, we estimate the correlation in wealth. We first look at correlations in ranks, and we then carry on to analyzing the correlation in the natural log of wealth, following the approach in Charles et al. (2013). Figure 6 further summarizes the previously described associations and provides the main result of our paper: trends in the correlation between partners' parental wealth by yearly union cohort. The graph shows that correlations are relatively small across the period and range between 0.04 and 0.19 . In general, the correlation appears highest when measuring parental wealth in the year of union formation (but not normalizing by father's age).

-Figure 6 about here-

Two measures show a slight decline in the correlation in the early 1990s, with the lowest correlations observed between 0.04 and 0.08 . This is followed by steady increases observed for all three measures thereafter and correlations peak at around 0.15-0.19 depending on the measure considered. When using parental wealth at union formation in both its forms (i.e. rank within the cohort, or rank within the cohort and paternal age groups) the correlation declines in recent years. When measuring parental wealth at age 18, the correlation keeps increasing until the end of the observation period. 
Even though a generally consistent trend of increasing parental wealth homogamy is observed across measures, there are some more subtle differences in the results depending on the measure employed, particularly once parental wealth is measured at age 18 . Do the different estimates based on parental wealth at 18 indicate that parental wealth during adolescence has a different effect on partnering than parental wealth at union formation? This is certainly a possibility. Alternatively, changes in the composition of wealth across periods may also drive results. For instance, parental wealth at age 18 is primarily measured before the financial crisis, which might have changed the composition of wealth in ways that affect the parental wealth correlation. To illustrate, negative parental wealth might both indicate an economically precarious situation but also access to credit (Killewald 2013). If the share of negative wealth changes over time, as Table 1 shows was the case in the period we observe, this might affect the parental wealth correlation even if partnering behavior remains constant.

More generally, how well parental wealth measured at a given point in time measures longterm family wealth (or other latent characteristics that affect partnering) may vary over time. For example, in periods of high wealth inequality, family wealth may be indicative of longterm access to wealth. These points raise the following questions: Are the trends we observe driven by periodic changes in the composition and characteristics of parental wealth and its distribution? Or are trends driven by actual changes in partnering behavior?

To test this argument, we further scrutinize the sensitivity of our results to the time at which parental wealth is measured in Figure 7. The solid line reproduces our original correlations of parental wealth measured at union formation (as observed in Figure 6; normalized by union cohort only). The thick dashed line displays parental wealth homogamy for couples that were formed five years earlier (i.e. five years before the year indicated on the x-axis). But, instead of measuring parental wealth during the year of union formation, parental wealth is measured five years after union formation, meaning in the year indicated on the x-axis. Given that this thick dashed line measures parental wealth homogamy for couples formed five years earlier, we should observe a five-year lag in the parental wealth homogamy trend, if partnering patterns are driving the evolution of our correlation. On the other hand, if our results are an artefact of the calendar year in which parental wealth is measured (due to period changes in the wealth composition), we should not observe a lag in the time trend over time at all once changing the couples for whom parental wealth homogamy is measured in a given calendar year.

-Figure 7 about here- 
The thick dashed line indicates that parental wealth homogamy trends move by several years once estimating parental wealth homogamy for couples formed five years before a given calendar year. To aid interpretation, the thin dashed line is added to Figure 7 which lags the original correlations in parental wealth homogamy (the solid line) with five years. It can be observed that the thick dashed line is close to the thin dashed line for most of the observation period (the beginning of the observation period being an exception). This indicates that we reach very similar substantive conclusions regardless of whether we measure parental wealth in the year of union formation or five years after union formation. Results are especially robust for the increases in homogamy observed during the 2000s. This reduces concerns that the observed increases in parental wealth homogamy are driven by a changing composition of wealth across calendar time and increases confidence in an interpretation that partnering changed over time.

At the same time, results are less consistent in the early 1990s. This illustrates that care has to be taken once interpreting correlations in parental wealth and comparing correlations across time and space. Indeed, this is a recommendation in general for research on wealth and trends in its effects over time.

\section{Robustness checks and comparison with Charles and colleagues' estimates}

The main results documented so far lead to two substantive conclusions: 1) estimates of parental wealth homogamy appear much lower in Denmark as compared to earlier estimates for the United States (Charles et al. 2013), but 2) parental wealth homogamy has become stronger over time. In the remainder of this section, we scrutinize both claims further. We present various robustness checks that will simultaneously make our results more comparable to those of Charles and co-authors' estimates for the United States.

In the following analysis, we take our results based on parental wealth measured at union formation (normalized by year) as the benchmark. This benchmark result (the solid line in the first graph of Figure 8) is identical to the one displayed in Figure 6. Figure 8 makes our results more comparable to the preferred estimate of Charles and colleagues in a step-by-step fashion.

-Figure 8 about here- 
First, we exclude cases where a parent had passed away before union formation, but for whom we recovered parental wealth information from earlier waves. Results are practically identical.

Second, we also exclude cases where parental wealth was negative in the year of union formation. Given that Charles and colleagues estimate of a 0.4 correlation relied on a measure of logged wealth, that correlation is based on a sample excluding cases with negative wealth. Once we exclude such cases with negative wealth from our analysis, the correlation drops for recent periods and trends over time become less pronounced. The reason for this weakening of the time trend can be found in Figure 4. Two particularly strong patterns of assortative mating arose from that heatmap: individuals from wealthy families partnering each other, and individuals from wealthy families avoiding individuals from families with low wealth. Excluding negative values largely takes out the latter part of the story from the data (i.e. negative wealth covers many of the lighter areas of Figure 4). Figure B3 available online displays an animated heatmap of how assortative mating patterns developed across union cohorts. ${ }^{11}$ It can be observed that individuals from the wealthiest families are increasingly less likely to partner individuals from families with low wealth and increasingly likely to partner at the top of the wealth distribution. Excluding negative wealth therefore excludes the former part of the story from the estimates and flattens the trend in parental wealth homogamy over time.

Third, instead of normalizing and calculating the rank of parental wealth at union formation, we log transform 3-year average wealth at union formation. Results are consistent, but the drop observed during the crisis years for the other measures now becomes less pronounced.

Fourth, following Charles and colleagues we also exclude cases with re-married parents, for whom the measurement in the United States data was not ideal. This specification does not change the conclusion that parental wealth homogamy in Denmark hovers around a correlation of 0.1 ; the time trend in the correlation is slightly more pronounced in this specification.

Fifth, switching from correlations to regression coefficients does not affect results. However, once adding controls for parents' ages, partners' ages and whether partners are foreign born in the final graph of Figure 8, the correlation between partners' parental wealth is reduced. In addition, the upward trend in the parental wealth association now largely disappears. Additional analysis (available upon request), indicated that controlling for parental ages shifts down the correlation across the period studied; a result also observed in Figure 6 once

${ }^{11}$ See also: https://media.giphy.com/media/64anFirdCTXZYWRirY/giphy.gif 
standardizing by father's age. The change in the time trend of coefficients is mainly produced by the inclusion of the two control variables for whether the male and female partner are foreign born. This might indicate that foreign born individuals are especially likely to form homogomous unions in terms of parental wealth, and that their share has been increasing (see Table 1). This final specification of Figure 8 represents the estimate that is closest to the specification presented by Charles and colleagues (2013). Further robustness checks included the exclusion of short cohabitation spells and the widening of the age range used for sample selection; results were robust to these further checks and are displayed in Online Appendix B.

In sum, the general conclusion that parental wealth homogamy in Denmark appears relatively low as compared to the 0.4 estimate for the United States (Charles et al. 2013) is robust across specifications. It has to be noted, however, that we are not able to gauge the possible influence of the different data sources used (survey data instead of registry data) as well as differences in sample selection (union cohorts versus a cross-section of unions intact at a given point in time).

The second conclusion of increasing parental wealth homogamy over time is less robust to the different sample selections and specifications chosen. Even though our initial estimates indicate an increase in homogamy across union cohorts, no trend is observed in the specification where all sample restrictions are applied and all controls are included. The increasing trend in homogamy disappears once we exclude cases with negative wealth and control for immigration status of the partners. Given that the former sample restriction selectively excludes couples from the analysis, and given that the latter controls for factors that are part of an explanation for trends in homogamy over time, we would argue that there is some support for the statement that parental wealth homogamy has been increasing over time. However, given the sensitivity of results to the model specification applied, we leave such claims for the discussion section.

\section{Discussion}

Who partners whom has been a central question for social scientists for several decades. Repeatedly, they have shown that partners match based on a variety of ascribed and acquired characteristics (Becker 1973, 1991; Blossfeld 2009; Browning et al. 2014; Kalmijn 1998; Lam 1988; Schwartz 2013; Weiss and Willis 1998). So far, surprisingly little attention has been paid 
to assortative mating based on parental wealth. Previous research on survey data from the United States estimated that parental wealth homogamy is relatively strong (Charles et al. 2013). High levels of parental wealth homogamy are likely to be consequential for wealth inequality between households, the transmission of family wealth across generations, and might be an indication of family wealth shaping boundaries between social groups. A major open question is therefore whether earlier findings of strong parental wealth homogamy hold once applied to a different setting and once using more accurate data.

In this paper, we show that the correlation in partners' parental wealth in Denmark is relatively weak. Correlations range between 0.04 and 0.19 , depending on the measure employed and the time period considered. This result contrasts the 0.4 correlation found by Charles and colleagues (2013) for the United States. In general, one might have expected parental wealth homogamy to be lower in Denmark due to its relatively high levels of intergenerational wealth mobility (indeed, low parental wealth homogamy might be a possible mechanism increasing mobility). However, the difference in the estimates between both countries is much larger than the difference found in cross-national comparisons of intergenerational wealth mobility (Boserup et al. 2013: 17). In addition, the relatively high levels of wealth inequality in Denmark (Balestra and Tonkin 2018) would lead to the expectation that wealth can be an important factor to be considered once making partner choices in Denmark too.

One might therefore question whether the large gap in estimates observed between studies reflects actual cross-national differences or whether variation in research design has led to a relatively large gap in estimates between studies. Even though we aimed at making our estimates comparable to those of Charles and colleagues (2013) - which actually led to even lower estimates of parental wealth homogamy - remaining major differences include the use of registry data instead of survey data and the study of unions in the year of formation rather than a cross-sectional selection of unions intact at a given point in time. More research is needed to understand whether the different types of data and empirical strategies employed affect results or not. But regardless of the reasons why, the main take-away point is that levels of parental wealth homogamy in Denmark are considerably weaker than what one might have expected based on estimates from previous research.

Nonetheless, even if levels of parental wealth homogamy are relatively low, this does not mean that assortative mating based on parental wealth is of little concern. Firstly, we found parental wealth homogamy to be particularly strong among partners from the wealthiest families. Given 
that a large share of wealth is owned by the top $10 \%$ of wealthiest households (Jakobsen et al. 2018), a concentration of parental wealth homogamy at the top can be consequential for wealth inequality, even if parental wealth homogamy is relatively low for the parental wealth distribution overall. Future research can explore further how consequential patterns of assortative mating based on parental wealth are for the distribution of wealth across households.

Secondly, even though levels of parental wealth homogamy were estimated to be relatively low in the early 1990s in Denmark, various estimations showed a steady increase in assortative mating during the late 1990s and the 2000s. Even though not all specifications showed the same trend in parental wealth homogamy over time, our preferred estimates suggest that there is an increasing tendency of homogamy among the very wealthy, as well as a decreasing likelihood of the very wealthy to partner with individuals from families with low wealth. These developments might lead to increasing social distances between the very wealthy (e.g. the "one per-cent") and those with little wealth in society. We also found indications that the increasing share of foreign-born individuals might have contributed to increased levels of parental wealth homogamy, as foreign-born individuals might both have less parental wealth and might encounter obstacles to partner with native-born individuals. It has to be noted, however, that the increases in the share of foreign-born individuals in our sample were relatively modest, and that additional possible interpretations of this result might therefore be needed to explain its impact on parental wealth homogamy trends. ${ }^{12}$ Future studies can further corroborate whether parental wealth homogamy has indeed been increasing and which mechanisms underlie these trends. If the conclusion of increasing parental wealth homogamy can be confirmed, this trend might not only be of concern for questions of wealth inequality, it is also surprising from a theoretical perspective. Most previous accounts of changes over time in the importance of parental characteristics suggested that the importance of 'ascribed characteristics' such as parental socioeconomic status decreased in importance over time (e.g. Kalmijn 1991; Rosenfeld 2008). Our study has shown that parental wealth might be an important exception.

A main objective of our study was to document the influence of various methodological choices on estimates of trends in assortative mating based on parental wealth. In this regard, several choices appeared relatively inconsequential for our results, such as the recovery of information

\footnotetext{
${ }^{12}$ Note also that due to our sample construction, these are foreign born individuals whose parents are in the sample. In other words, parents have to live in Denmark in order to measure parental wealth. Our analysis therefore largely excludes foreign born individuals who came to Denmark without their parents.
} 
on parental wealth from parents who had passed away at the time of union formation, the exclusion of short cohabitation spells, and using a log transformation instead of ranks. At the same time, other choices appeared to be important for the conclusions of our study.

Firtstly, the choice of when to measure parental wealth. Parental wealth is a time-varying measure and the extent to which it is an indicator of long-term access to economic resources is likely to vary across periods (e.g. with the business cycle). Our analysis revealed that the increases in parental wealth homogamy observed between the 1990s and 2000s were not sensitive to the time of measurement. However, this appeared to be less the case for the decreasing trend in homogamy found for the start of our observation window. A recommendation for future research is therefore to take particular care once interpreting and comparing correlations in parental wealth, and indeed the correlation of wealth with any characteristic, across time and space.

Secondly, the exclusion of cases with negative wealth changed the estimated time trend in parental wealth homogamy. Even though excluding such cases might be motivated by methodological choices (e.g. a preference for logged transformed wealth rather than ranks) or data constraints (e.g. wealth is often only available on the household level complicating the inclusion of re-married parents), the results of this paper have shown that they are consequential for the substantive conclusions reached. It is therefore recommendable for future research to pay particular attention to how estimates of parental wealth homogamy can be made comparable across studies and contexts.

To conclude, this study has shown that parental wealth homogamy in Denmark is lower than what one would have expected based on earlier research. At the same time, homogamy is shown to be disproportionately strong at the top of the parental wealth distribution. This might be particularly consequential for wealth inequality between households, as wealth is so strongly concentrated at the very top. Furthermore, there are indications that parental wealth homogamy has been increasing over time. There hence appear to be social boundaries between the wealthiest in society and the rest of the population, and these boundaries might have become stronger over time. Our work underlines the importance of studying assortative mating and its trends over time for a better understanding of one of the major processes generating wealth inequality between households. Further, we think that important insights can be gained from continuing to study homogamy in parental wealth, in particular as wealth inequality continues 
to rise in many places and as we wonder how social boundaries between groups will co-evolve with these inequalities. 


\section{References}

Balestra, C. \& Tonkin, R. (2018) Inequalities in household wealth across OECD countries: Evidence from the OECD Wealth Distribution Database. OECD Statistics Working Papers, No. 2018/01, doi.org/10.1787/7e1bf673-en

Barro, R. J., \& Lee, J. W. (2015). Education matters. Global schooling gains from the 19th to the 21st century. Oxford: Oxford University Press.

Becker, G.S. (1973). A theory of marriage: Part I. Journal of Political Economy, 81, 813-846.

Becker, G.S. (1991). A Treatise on the Family. Cambridge: Harvard University Press.

Blossfeld, H. P. (2009). Educational assortative marriage in comparative perspective. Annual Review of Sociology, 35, 513-530.

Boserup, S. H., Kopczuk, W., \& Kreiner, C. T. (2013). Intergenerational wealth mobility: Evidence from danish wealth records of three generations. Working Paper, University of $\begin{array}{llll}\text { Copenhagen. } & \text { 27/03/2019 }\end{array}$ http://citeseerx.ist.psu.edu/viewdoc/download?doi=10.1.1.593.4714\&rep=rep1\&type=pdf

Boserup, S. H., Kopczuk, W., \& Kreiner, C. T. (2018). Born with a silver spoon? Danish evidence on wealth inequality in childhood. The Economic Journal, 128(612), F514-F544.

Browning, M., Mette G. \& Leth-Petersen, S. (2013). Housing Wealth and Consumption: A Micro Panel Study. Economic Journal, 123(568), 401-428.

Browning, M., Weiss, Y., Chiappori, P.A. (2014). Economics of the Family. Cambridge: Cambridge University Press.

Charles, K. K., \& Hurst, E. (2002). The transition to home ownership and the black-white wealth gap. The Review of Economics and Statistics, 84(2), 281-297. doi: $10.1162 / 003465302317411532$

Charles, K. K., Hurst, E., \& Killewald, A. (2013). Marital sorting and parental wealth. Demography, 50(1), 51-70.

Danish Economic Council (2016): Dansk Økonomi. Autumn 2016. Chapter V.

Drefahl, S. (2012). Do the married really live longer? The role of cohabitation and socioeconomic status. Journal of Marriage and Family, 74(3), 462-475.

Eads, A., \& Tach, L. (2016). Wealth and Inequality in the Stability of Romantic Relationships. The Russell Sage Foundation Journal of the Social Sciences, 2(6), 197-224.

Fremeaux, N. (2014). The role of inheritance and labour income in marital choices. Population, 69(4), 495-530.

Gould, E. D., \& Paserman, M. D. (2003). Waiting for Mr. Right: rising inequality and declining marriage rates. Journal of Urban Economics, 53(2), 257-281. 
Henz, U., \& Mills, C. (2018). Social class origin and assortative mating in Britain, 1949-2010. Sociology, 52(6), 1217-1236.

Jakobsen, K., Jakobsen, K., Kleven, H., \& Zucman, G. (2018). Wealth taxation and wealth accumulation: Theory and evidence from Denmark. NBER Working Paper, No. 24371. National Bureau of Economic Research.

Kalmijn, M. (1991). Shifting boundaries: Trends in religious and educational homogamy. American Sociological Review, 56, 786-800.

Kalmijn, M. (1998). Intermarriage and homogamy: Causes, patterns, trends. Annual Review of Sociology, 24(1), 395-421.

Killewald, A. (2013). Return to being black, living in the red: A race gap in wealth that goes beyond social origins. Demography, 50(4), 1177-1195.

Killewald, A., Pfeffer, F.T., \& Schachner, J.N. (2017) Wealth Inequality and Accumulation. Annual Review of Sociology, 43, 35.1-35.26. doi: 10.1146/annurev-soc-060116-053331.

Kopczuk, W., \& Lupton, J. P. (2007). To leave or not to leave: The distribution of bequest motives. The Review of Economic Studies, 74(1), 207-235.

Kremer, M. (1997). How Much does Sorting Increase Inequality? The Quarterly Journal of Economics, 112(1), 115-139

Lam, D. (1988). Marriage Markets and Assortative Mating with Household Public Goods: Theoretical Results and Empirical Implications. Journal of Human Resources, 23(4), 462487.

Monaghan, D. (2015). Income inequality and educational assortative mating: Evidence from the Luxembourg Income Study. Social Science Research, 52, 253-269.

Pencavel, J. (1998). Assortative Mating by Schooling and the Work Behavior of Wives and Husbands. The American Economic Review, 88(2), 326-329

Pfeffer, F. T. (2011). Status Attainment and Wealth in the United States and Germany. In: Smeeding, T., Erikson, R. \& Jäntti, M. (Eds.), Persistence, Privilege, and Parenting. The Comparative Study of Intergenerational Mobility (pp. 109-137). New York: Russell Sage Foundation.

Pfeffer, F. T. (2018). Growing Wealth Gaps in Education. Demography, 55(3), 1033-1068.

Pfeffer, F. T. \& Schoeni, R. F. (2016). How Wealth Inequality Shapes Our Future. RSF: The Russell Sage Foundation Journal of the Social Sciences, 2(6), 2-22

Piketty, T. (2014). Capital in the 21st Century. Cambridge: Harvard University 
Rauscher, E. (2016). Passing it on: Parent-to-adult child financial transfers for school and socioeconomic attainment. RSF: The Russell Sage Foundation Journal of the Social Sciences 2(6), 172-196.

Rosenfeld, M. J. (2008). Racial, educational and religious endogamy in the United States: A comparative historical perspective. Social Forces, 87(1), 1-31.

Rosenfeld, M. J., \& Kim, B. S. (2005). The independence of young adults and the rise of interracial and same-sex unions. American Sociological Review, 70(4), 541-562.

Schneider, D. (2011). Wealth and the marital divide. American Journal of Sociology, 117(2), 627-667.

Schwartz, C.R. (2010). Earnings inequality and the changing association between spouses' earnings. American Journal of Sociology, 115(5), 1524-1557.

Schwartz, C.R. (2013). Trends and variation in assortative mating: Causes and consequences. Annual Review of Sociology, 39, 451-470.

Schwartz, C. R., \& Mare, R. D. (2005). Trends in educational assortative marriage from 1940 to 2003. Demography, 42(4), 621-646.

Smith, J. A., McPherson, M., \& Smith-Lovin, L. (2014). Social distance in the United States: Sex, race, religion, age, and education homophily among confidants, 1985 to 2004. American Sociological Review, 79(3), 432-456.

Solon, G. (2004). A model of intergenerational mobility variation over time and place. In: Corak, M. (ed.) Generational income mobility in North America and Europe. Cambridge: Cambridge University Press

Spilerman, S. (2000). Wealth and stratification processes. Annual Review of Sociology, 26(1), 497-524. doi:10.1146/annurev.soc.26.1.497

Thompson, J., \& Conley, D. (2016). Health Shocks and Social Drift: Examining the Relationship Between Acute Illness and Family Wealth. The Russell Sage Foundation Journal of the Social Sciences, 2(6), 153-171.

Torche, F. (2010). Educational assortative mating and economic inequality: A comparative analysis of three Latin American countries. Demography, 47(2), 481-502.

Weiss, Y., \& R. Willis (1997). Match Quality, New Information and Marital Dissolution. Journal of Labor Economics, 15:293-329. 


\section{Tables}

Table 1. Descriptive Statistics of Couples at Union Formation; $N=803,185$

\begin{tabular}{|c|c|c|c|c|}
\hline \multirow[b]{2}{*}{ Variable } & \multicolumn{2}{|c|}{ All Sample } & \multirow{2}{*}{$\begin{array}{l}1987 \\
\text { Mean }\end{array}$} & \multirow{2}{*}{$\begin{array}{l}\mathbf{2 0 1 3} \\
\text { Mean }\end{array}$} \\
\hline & Mean & SD & & \\
\hline \multicolumn{5}{|l|}{ Female Partners' Characteristics } \\
\hline Age & 24.3 & 3.6 & 23.3 & 24.4 \\
\hline Education: ISCED 1-2 & .32 & .47 & .44 & .29 \\
\hline ISCED 3-4 & .54 & .50 & .47 & .51 \\
\hline ISCED 5-6 & .14 & .34 & .09 & .20 \\
\hline Mother's Age & 50.7 & 6.1 & 49.0 & 52.4 \\
\hline Father's Age & 53.5 & 6.7 & 52.4 & 55.0 \\
\hline Married at Union Formation & .06 & .23 & .09 & .04 \\
\hline Foreign Born & .01 & .09 & .00 & .02 \\
\hline Parents' Annual Wealth at Offspring Union Formation (x10000 kr.) & 91.5 & 422.7 & 59.9 & 72.9 \\
\hline Parents' 3-year Average Wealth at Union Formation (x10000 kr.) & 87.6 & 496.4 & 70.1 & 74.8 \\
\hline Parents' 3-year Average Wealth at Union Formation Negative & .27 & .45 & 0.20 & 0.39 \\
\hline \multicolumn{5}{|l|}{ Male Partners' Characteristics } \\
\hline Age & 26.1 & 3.7 & 25.3 & 26.1 \\
\hline Education: ISCED 1-2 & .27 & .45 & .33 & .27 \\
\hline ISCED 3-4 & .58 & .49 & .57 & .55 \\
\hline ISCED 5-6 & .14 & .35 & .10 & .19 \\
\hline Mother's Age & 52.4 & 6.1 & 51.3 & 54.7 \\
\hline Father's Age & 55.2 & 6.7 & 53.7 & 56.4 \\
\hline Married at Union Formation & .05 & .22 & .08 & .04 \\
\hline Foreign Born & .01 & .10 & .00 & .02 \\
\hline Parents' Annual Wealth at Offspring Union Formation (x10000 kr.) & 99.2 & 470.7 & 68.5 & 87.6 \\
\hline Parents' 3-year Average Wealth at Union Formation (x10000 kr.) & 95.4 & 422.1 & 78.9 & 88.9 \\
\hline Parents' 3-year Average Wealth at Union Formation Negative & .25 & .43 & .18 & .35 \\
\hline \multicolumn{5}{|l|}{ Parents' Characteristics } \\
\hline Married to Other Parent at Offspring Union Formation & .67 & .35 & .77 & .56 \\
\hline Cohabiting with Other Parent at Offspring Union Formation & .02 & .09 & .01 & .03 \\
\hline Single or Widow(er) at Offspring Union Formation & .16 & .23 & .12 & .21 \\
\hline Re-Partnered at Offspring Union Formation & .05 & .12 & .04 & .07 \\
\hline Re-Married at Offspring Union Formation & .10 & .18 & .07 & .12 \\
\hline
\end{tabular}

Note. Descriptive statistics for sample with information on 3-year average wealth at union formation. Both male and female partner aged between 18 and 34 at union formation. Data for the year 2013 is missing for education, the value in the 2013 column is for 2012 . 


\section{Figures}

Figure 1. Composition of wealth by parental wealth percentile

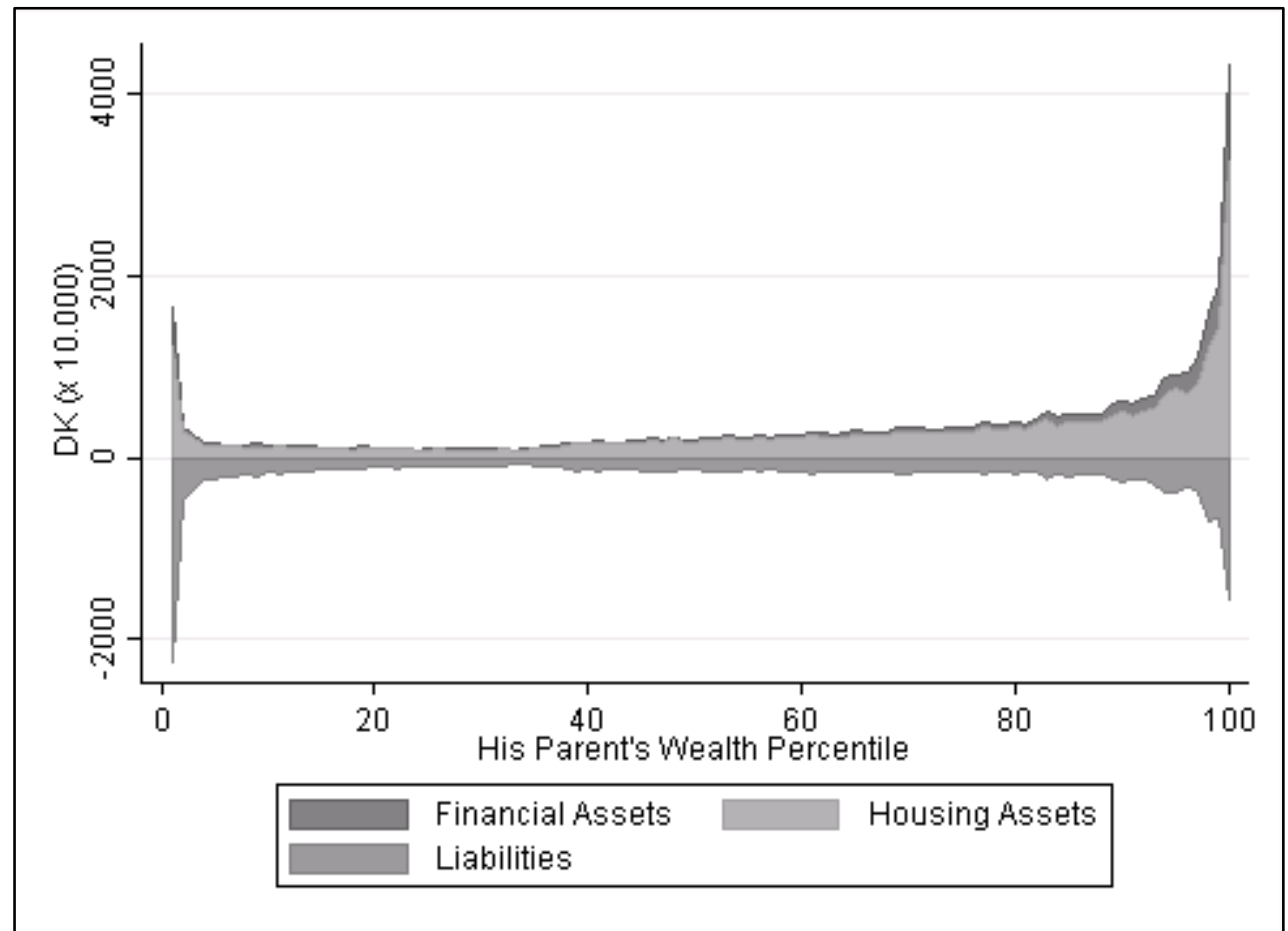

Note. Pooled sample 1987-2013; Within-cohort wealth percentiles of the male partner in the year of union formation. $\mathrm{N}=803,185$ 
Figure 2. Median and average parental wealth by year

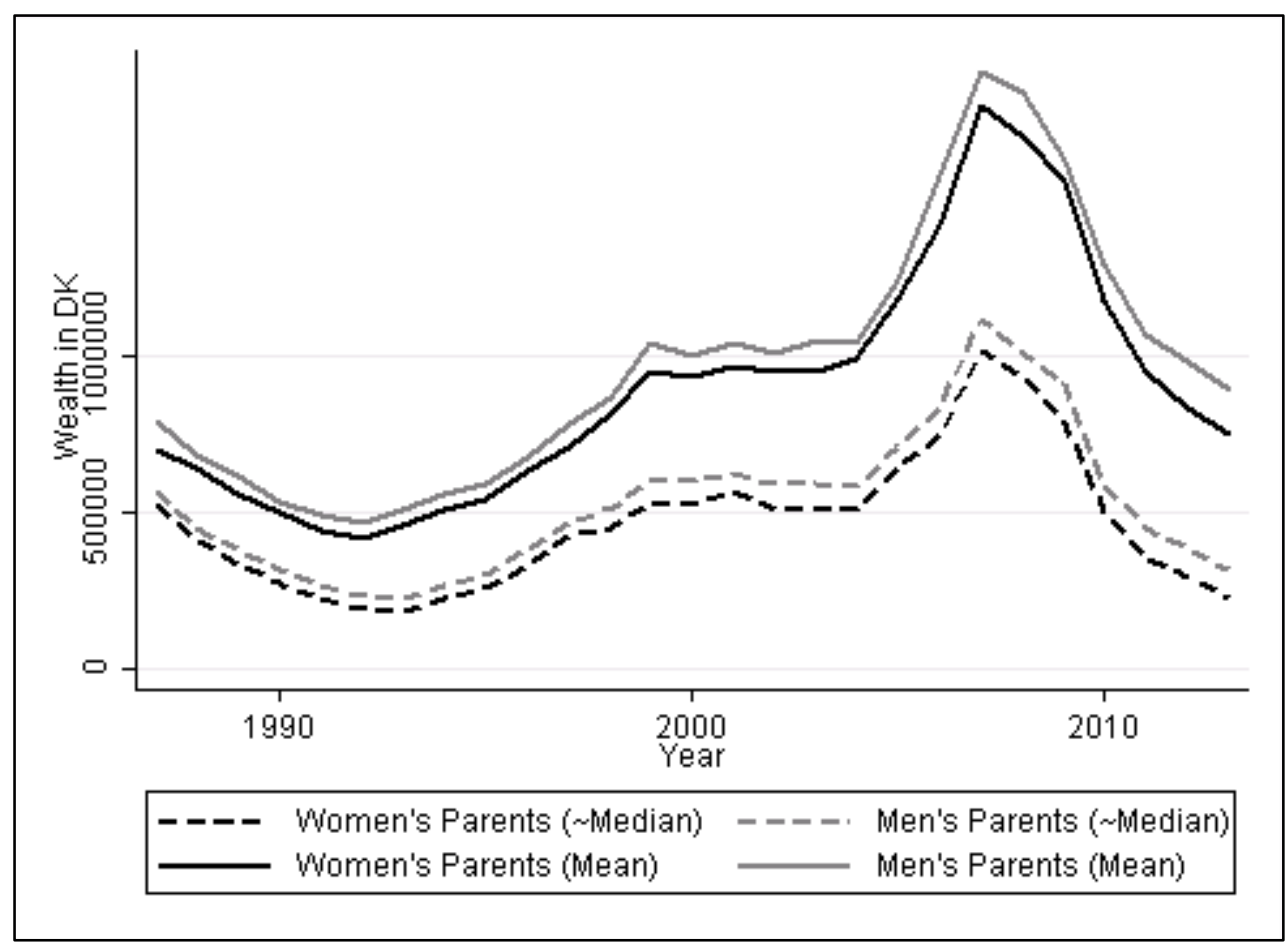

Note. Average (solid lines) and median (dashed lines) sum of parental wealth at year of union formation. $\mathrm{N}=$ 803,185 . Due to data restrictions, the median is approximated by taking the sum of the $48^{\text {th }}$ to $52^{\text {nd }}$ percentile divided by five; Wealth is measured in 2010 price levels. 
Figure 3. Inequality in untransformed parental wealth (at union formation) by year (Gini)

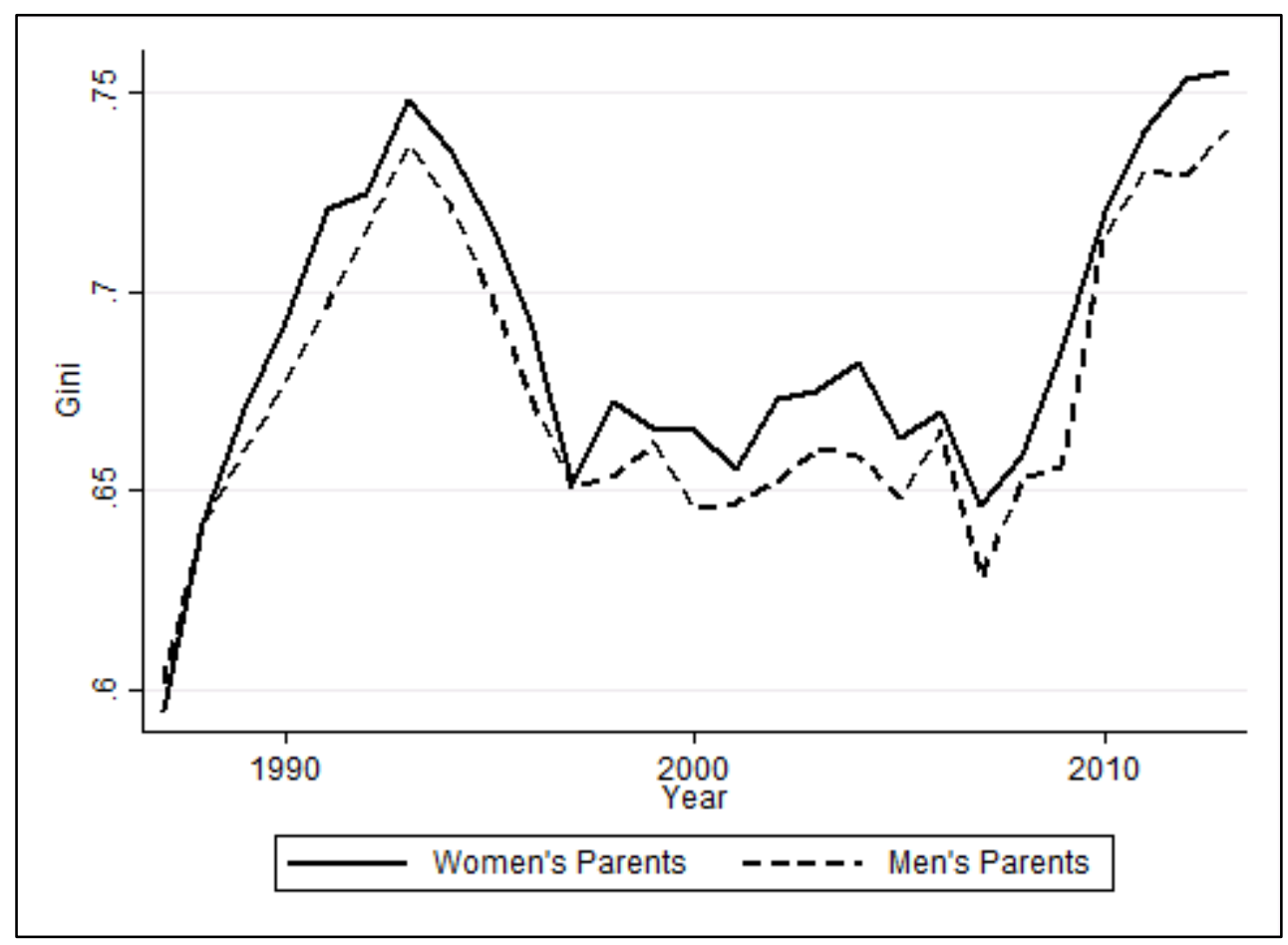

Note. Three-year averaged parental wealth at year of union formation. $\mathrm{N}=803,185$ 
Figure 4. Heatmap of relative frequency of couple combinations based on parental wealth $1987-2013$

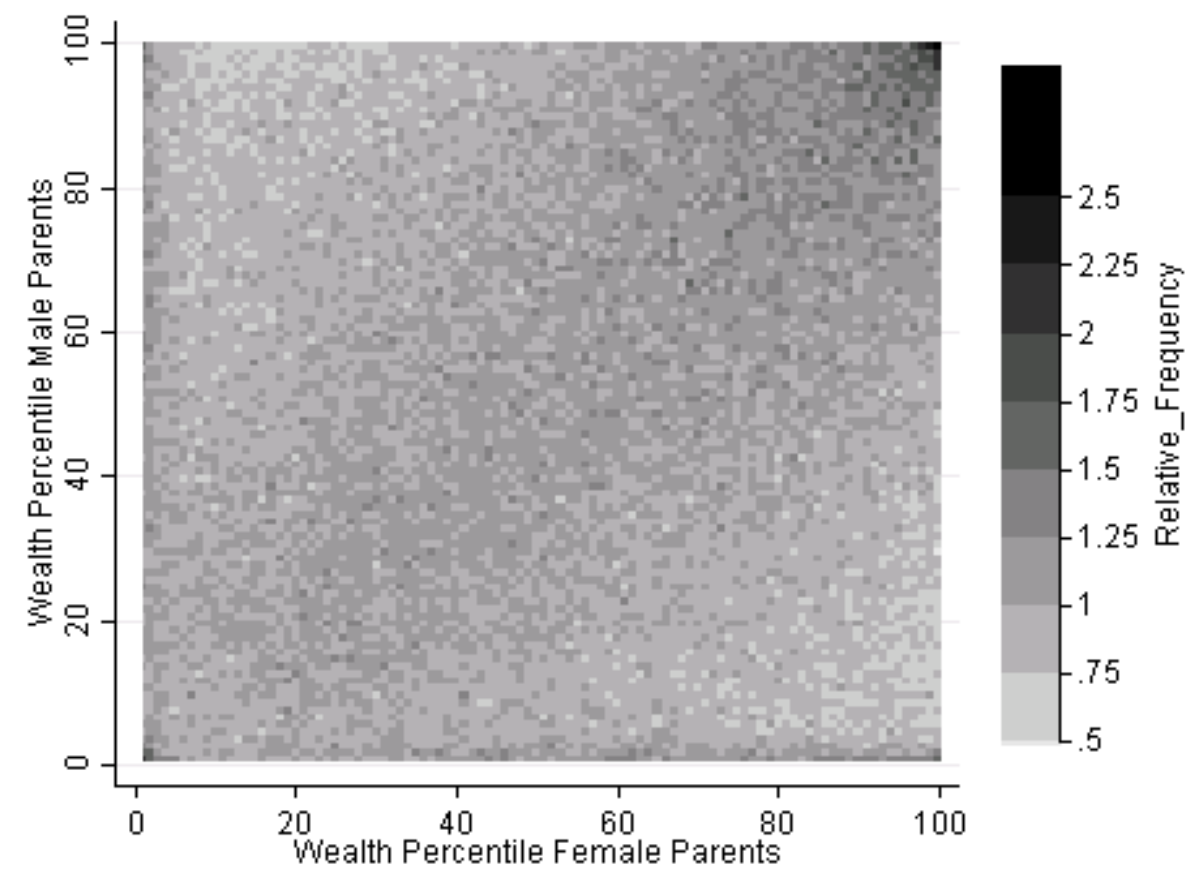

Note. Parental wealth percentile at union formation within union cohort. Frequency indicates relative frequency of combination of parental wealth percentiles; a value of one indicates relative frequency as expected based on random mating. Pooled results for complete period 1987-2013. $\mathrm{N}=803,185$ 
Figure 5. Average Men's Parental Wealth Percentile at Union Formation by Women's Parental Wealth Percentile at Union Formation

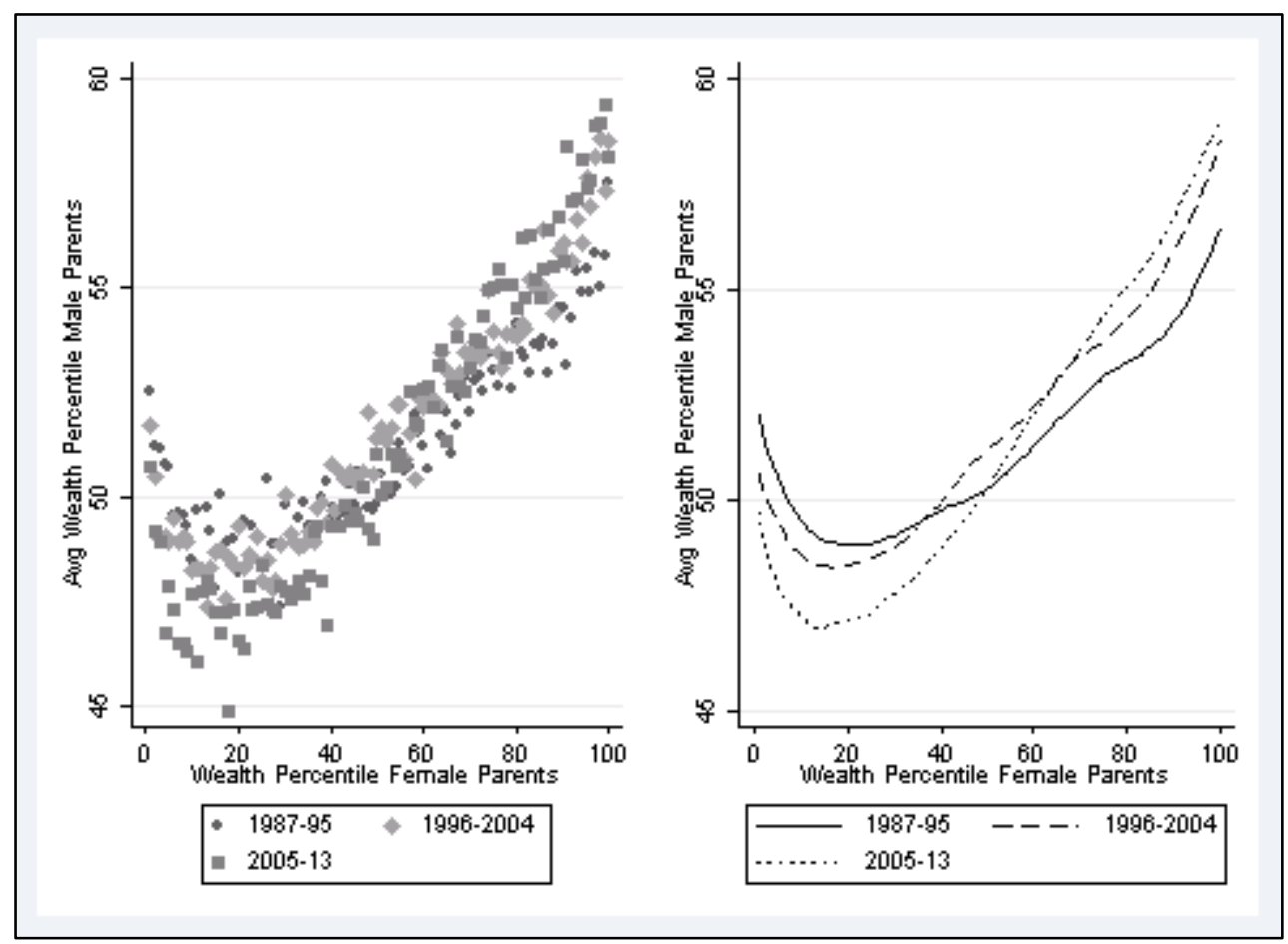

Note. Left pane: Average wealth percentile of male parents calculated separately for each percentile of female partners' parental wealth. Right pane: Smoothened line based on dots of left pane. 
Figure 6. Correlation between her and his parental wealth at union formation by year

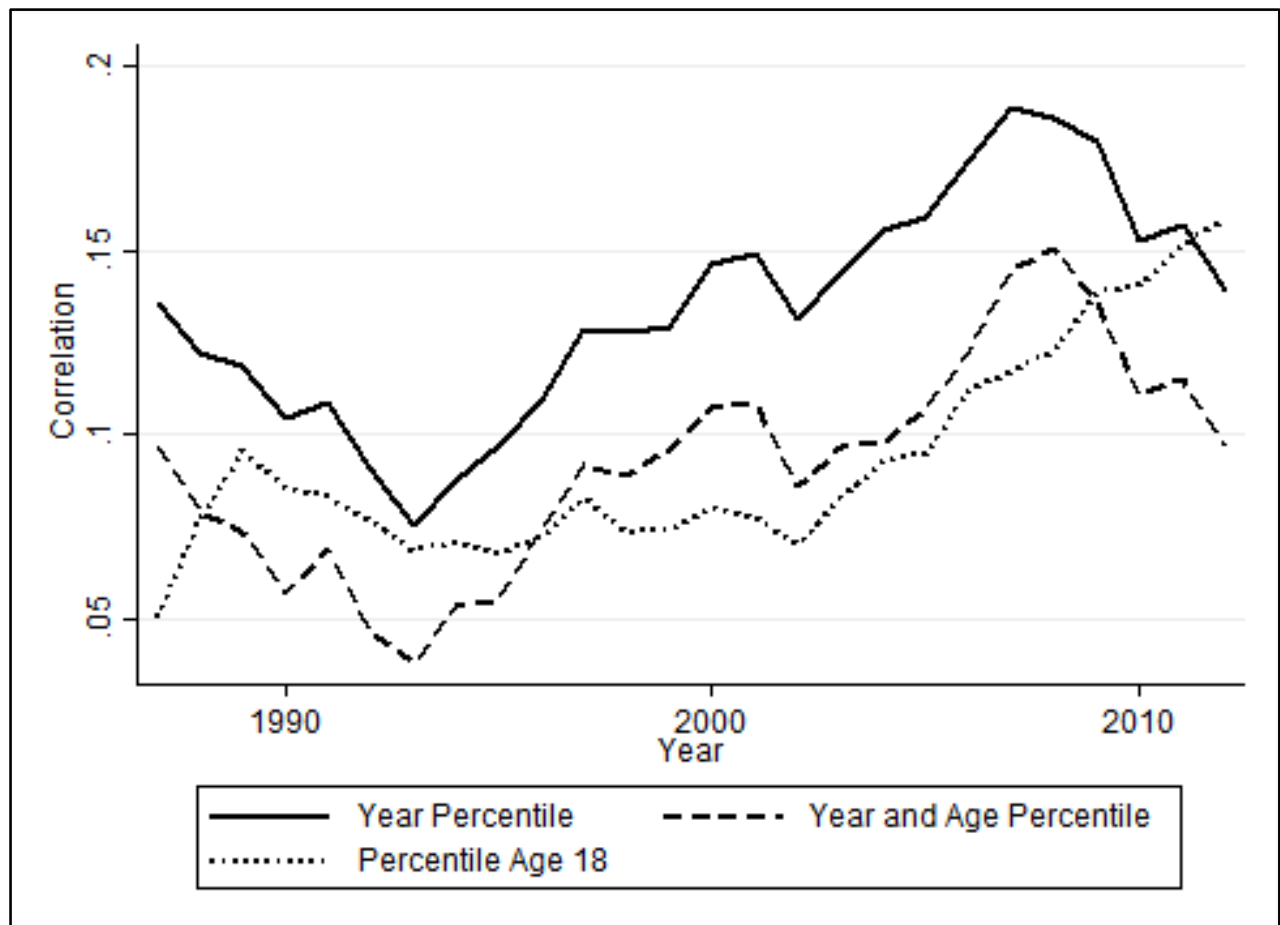

Note. Year Percentile $=$ pw1: Parental Wealth Measured at Union Formation, rank within union cohort; Year and age percentile $=$ pw2: Parental Wealth Measured at Union Formation, normalized by paternal age within a given union cohort, and subsequently ranked within union cohort; Percentile Age $18=$ pw3: Parental wealth measured at age 18 , normalized for age cohort, ranked within union cohort. $\mathrm{N}=803,185$ 
Figure 7. Sensitivity of parental wealth correlation to time of measurement

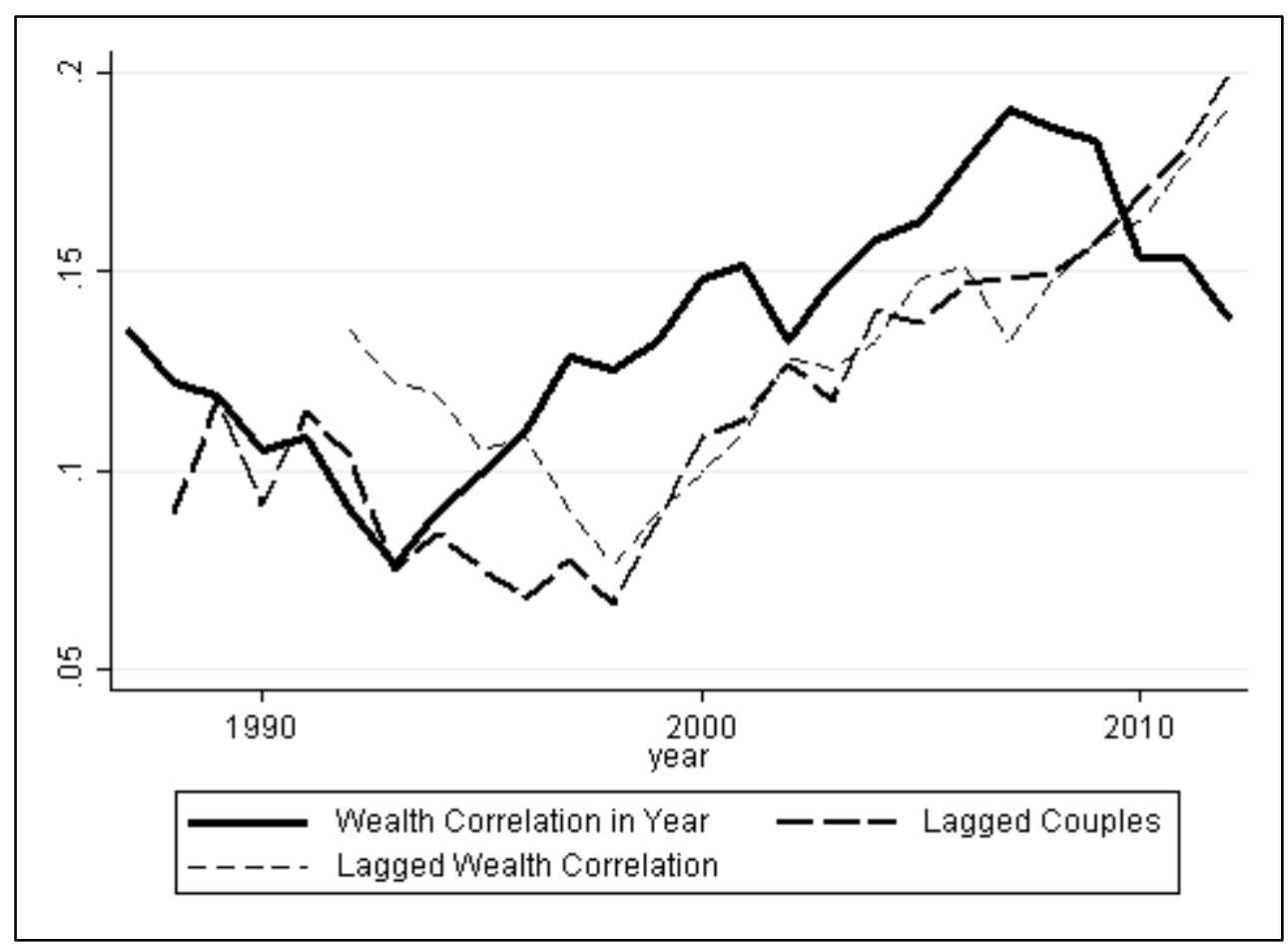

Note. Solid line $=$ Correlation in parental wealth measured at union formation, rank within union cohort; Thin dashed line $=$ Correlation in parental wealth measured at union formation for couples formed five years before year of reference; Thick dashed line $=$ Correlation in parental wealth measured five years after union formation for couples formed five years before year of reference. 
Figure 8. Replication of main results using various specifications and sample restrictions

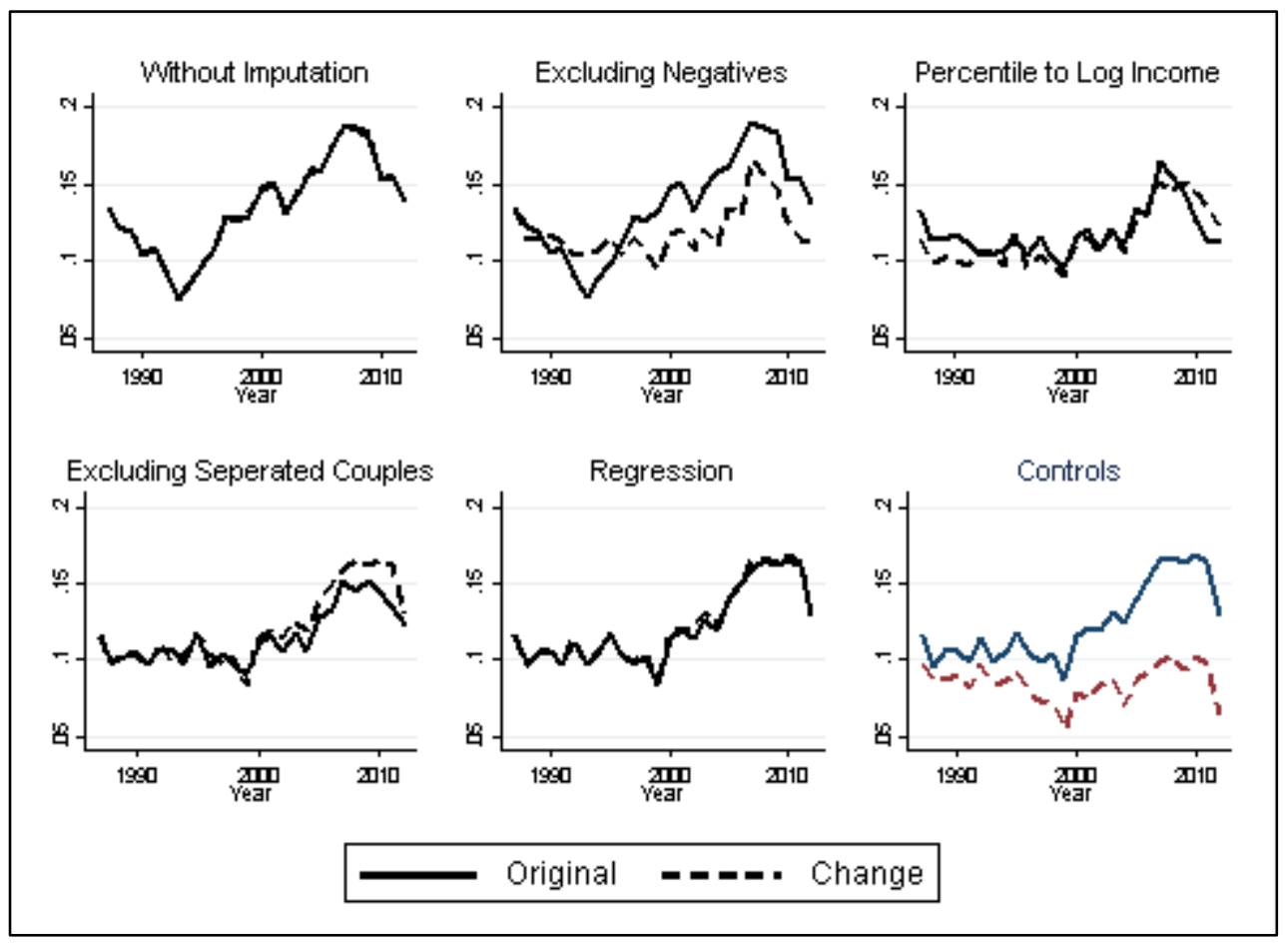

Note. Graphs gradually add sample restrictions or model specifications. Each graph displays reproduces the dashed line of the previous graph as a solid line, and shows the additional change in estimates once adding the sample restriction/model specification referred to through the dashed line. Without Imputation = Solid line is correlation in parental wealth measured at union formation, rank within union cohort; Dashed line is as solid line but excluding cases where a parent passed away before union formation; Excluding negatives $=$ Dashed line as without imputation but also excludes individuals with negative wealth from the sample; Percentile to Log Income $=$ As Excluding Negatives but uses logged absolute parental wealth rather than parental wealth rank. Excluding Separated Couples $=$ As Percentile to Log Income but excluding individuals whose parents re-married before union formation. Regression $=$ As excluding separated couples but OLS regression coefficients rather than correlations. Controls = As Regression but including controls for mothers' age, fathers' age, his age, her age, he foreign born and she foreign born. 


\section{Online Appendix}

\section{A. Presence of Parental Identification Numbers and Parents in the Registry Data}

The requirement for inclusion in the sample of our study was the identification of both parents in the wealth data. Parents were not identified in the data if: 1) Parental identification numbers were not available that allowed us to link parents to children in the registry data. Such parental identification numbers were provided for all individuals born after 1960, but were incomplete for earlier birth cohorts (Boserup et al. 2013). 2) Parents had passed away before 1980, moved away from Denmark before 1980, or never lived in Denmark. Given that our information on wealth is available for the period 1980-2013, we do not have information on parental wealth in such cases.

In this Online Appendix we present robustness checks that reduced concerns that the exclusion of these cases affected our conclusions. Figure A1 shows the percentage of unions formed in each year for which we did not identify all four parents in the dataset. The thick blue line represents the final sample used in the main analysis. The non-identification of parents can arise due to two main reasons:

1) Parental identification numbers are not available for one of the four parents involved. The red dashed line indicates the share of cases that has parental id's available for all parents. Between 12 and 21 percent of cases do not have parental identification numbers, and this is relatively stable across calendar time.

2) Parents might have passed away or do not live in Denmark, and we did not manage to recover information on parental wealth from earlier years. The dashed blue line indicates cases where parents were not present in the data in the year of union formation. This applies to a bit less than $20 \%$ of the overall sample (difference between red and blue dashed lines). Whenever we were able to recover parental wealth from earlier waves (the last wave both parents were still alive), we pulled this wealth information forward after normalizing wealth within the distribution of the original year and included it in our wealth rank at union formation. This applies to less than 5\% of cases. Robustness checks including these cases generated identical results (Figure 7).

Even though the distribution of cases where parents were not identified is relatively stable across calendar time, this is not the case once looking at the distribution according to age. The 
left panes of Figures A2-A4 show how the availability of parental identification numbers declines steadily with age. Given that parental identification numbers were available for all individuals born after 1961 only, the age profile of missing parent id's changes with calendar time. Especially in 1987, the start of our observation window, availability of parent id's declines steeply with age. Given that availability of parent id's drops to practically zero after age 35, we restricted our sample to unions formed before age 35. Things look a bit better in 1993, where we also have cases aged 40 with parental identification numbers available. Robustness checks extending the analysis to unions formed before age 40 (See Figure B1) should are therefore most reliable from 1993 onward. The changing age profile of missing parental identification numbers might influence our estimates of correlations in parental wealth across time. If older (or younger) couples are more likely to be homogomous, their underrepresentation in older cohorts might drive down (or up) the parental wealth correlation. To check whether this was of concern we re-ran our analysis where we reweighted couples based on the probability that the couple had all four parent identification numbers available in the data. This probability was calculated based on the percentage of individuals of a given birth cohort (by year) that had both parental identification numbers available. For each union formed, we multiplied the probability of both partners with each other and divided 1 by that quantity (i.e. $1 /$ (probability male* probability female). These results were used to reweight the analysis in robustness checks. The second panes of Figures A1-A4 show how missing parental identification numbers are more equally distributed across calendar time and age once reweighting. Figure A5 shows how including these weights in our analysis reproduces our main results of Figure 3 very well. 
Figure A1. Percentage of couples with at least one parent not identified; split by reason (missing parent id, parent not present in data in year of union formation)
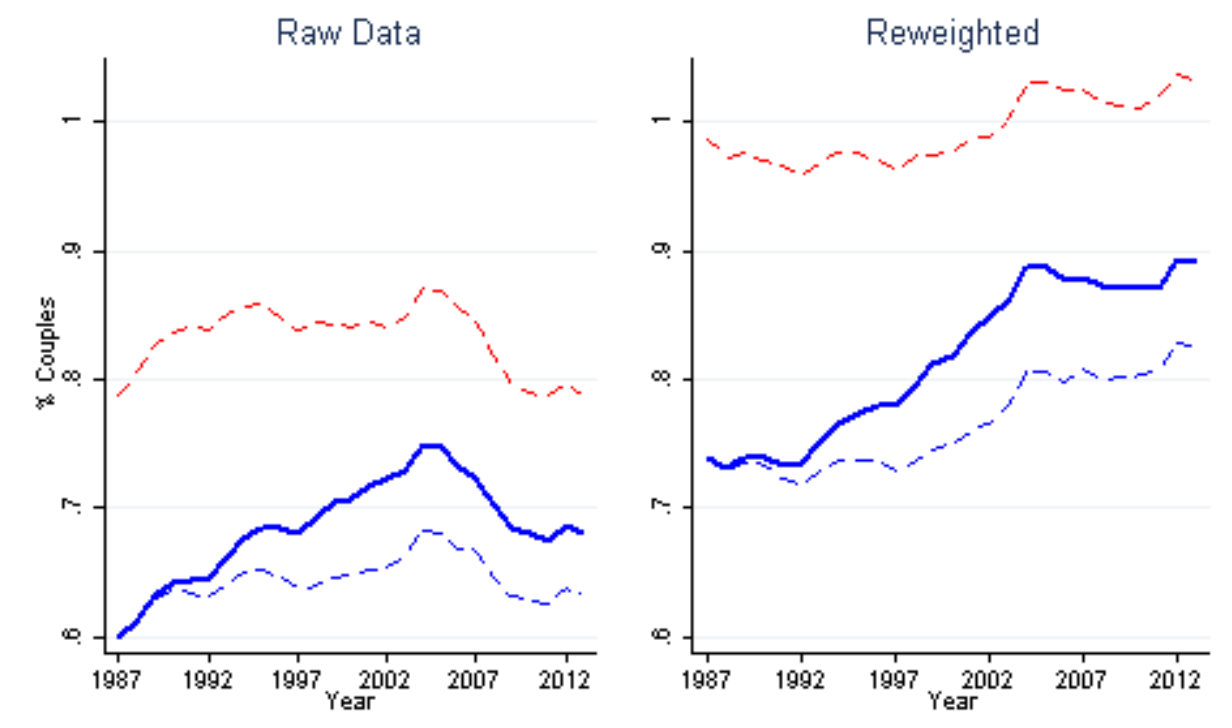

----- Parent ID

Parent Wealth: Imputation

Parent Wealth: No Imputation 
Figure A2-A4. Percentage of couples with at least one parent not identified; split by reason (missing parent id, parent not present in data in year of union formation). By age for all sample, 87 and 1993.
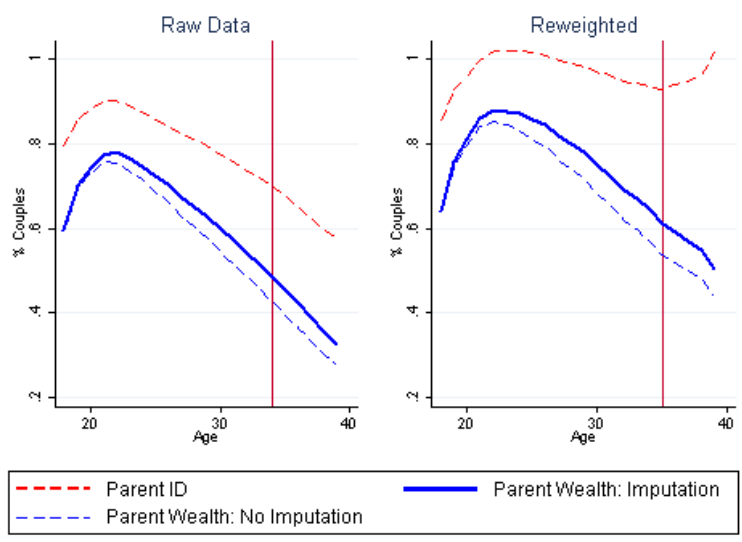

Data Availability by Age (Male Partner) 1987
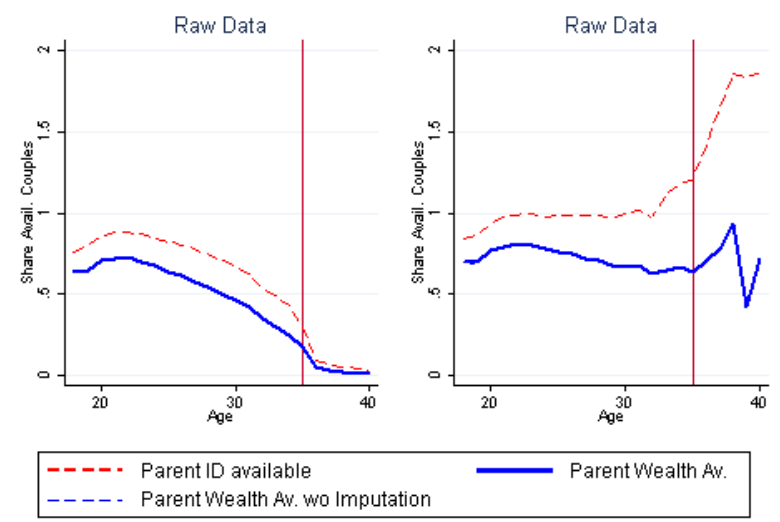

Data Availability by Age (Male Partner) 1993
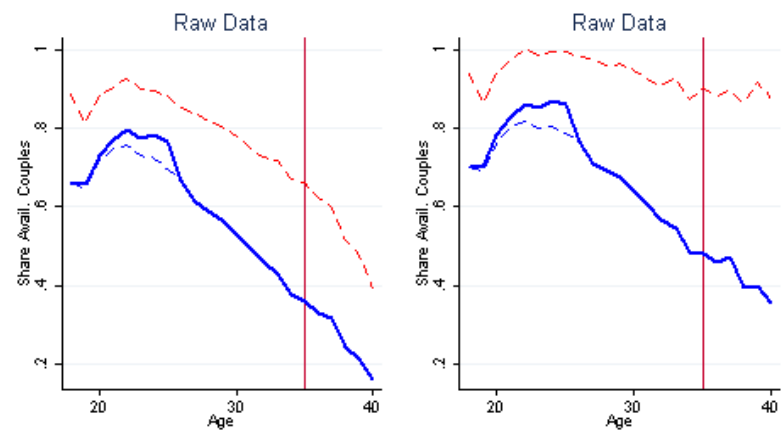

---- Parent ID available

Parent Wealth Av. wo Imputation

Parent Wealth Av. 
Figure A5. Replication of Figure 6 including weights

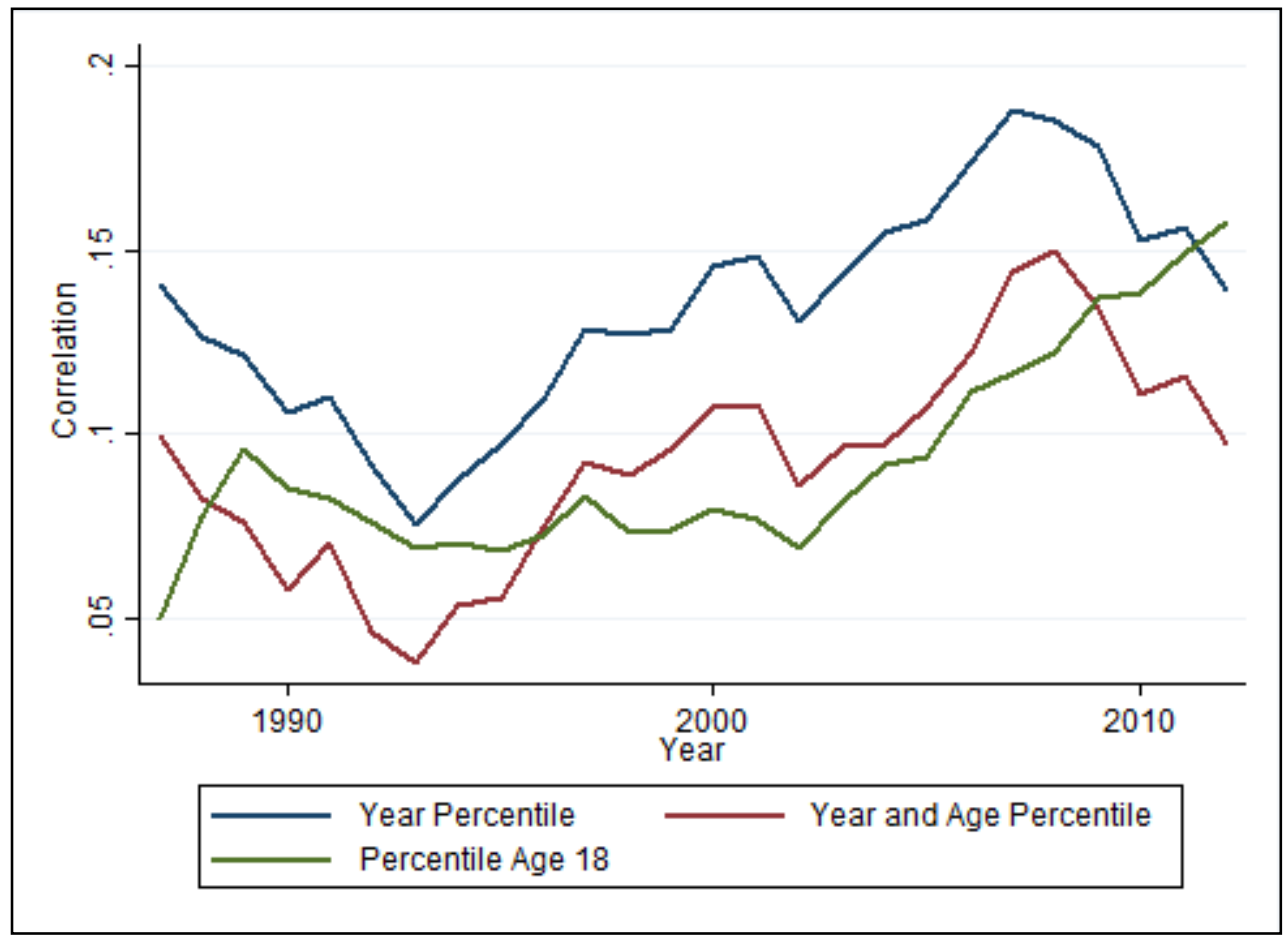


Figure B1. Replication of main result with different age cut-off

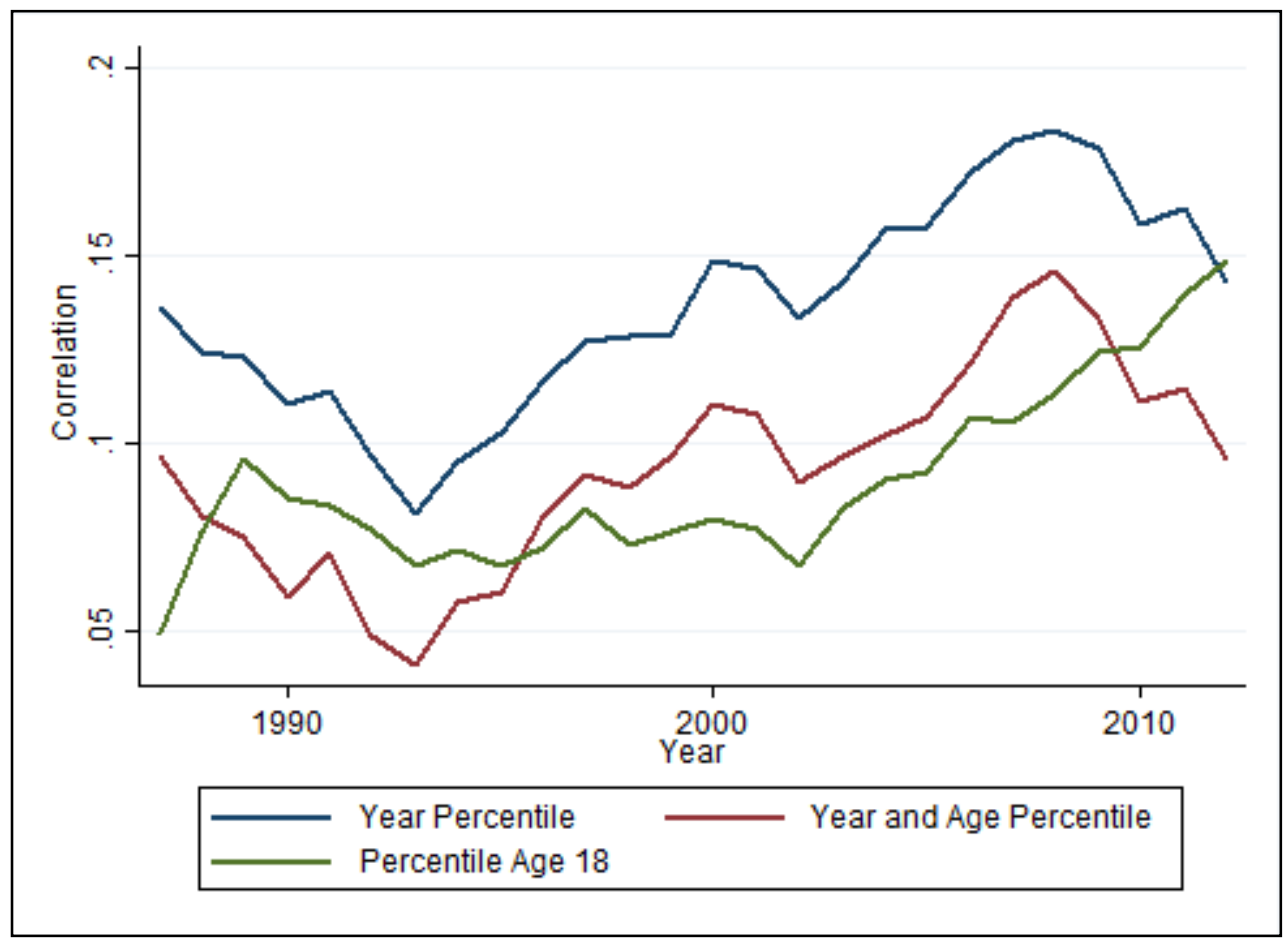

Note. Replication of Figure 6 expanding age range of partners included in the sample to 1839 years 
Figure B2. Replication of main result excluding short-lived relationships

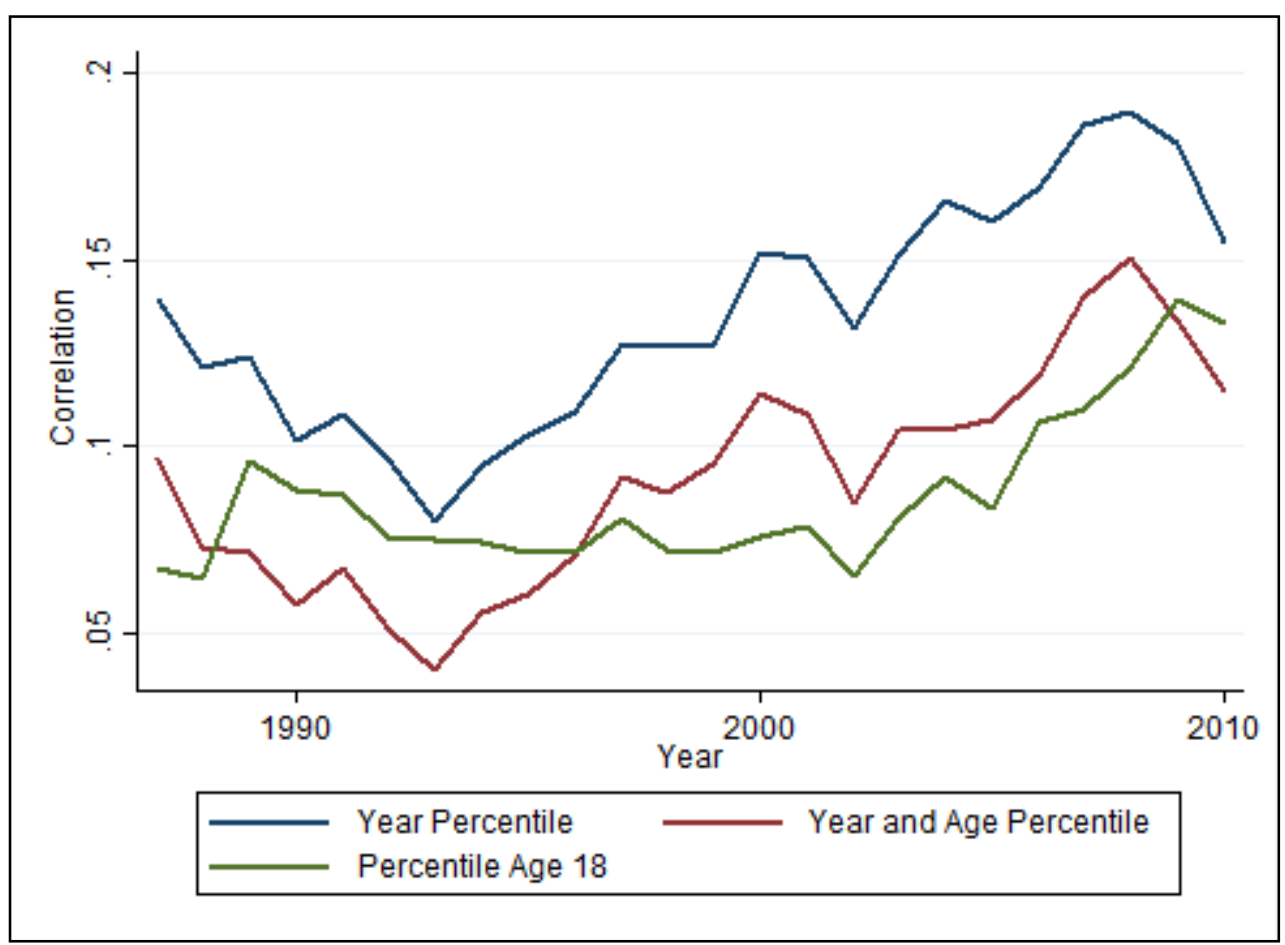

Note. Replication of Figure 6 excluding cohabiting unions that lasted less than three years 
Figure B3. Animated heatmap of relative frequency of particular couple combinations based on parental wealth 1987-2013

Animation: https://media.giphy.com/media/64anFirdCTXZYWRirY/giphy.gif

Yearly graphs not animated (in color):
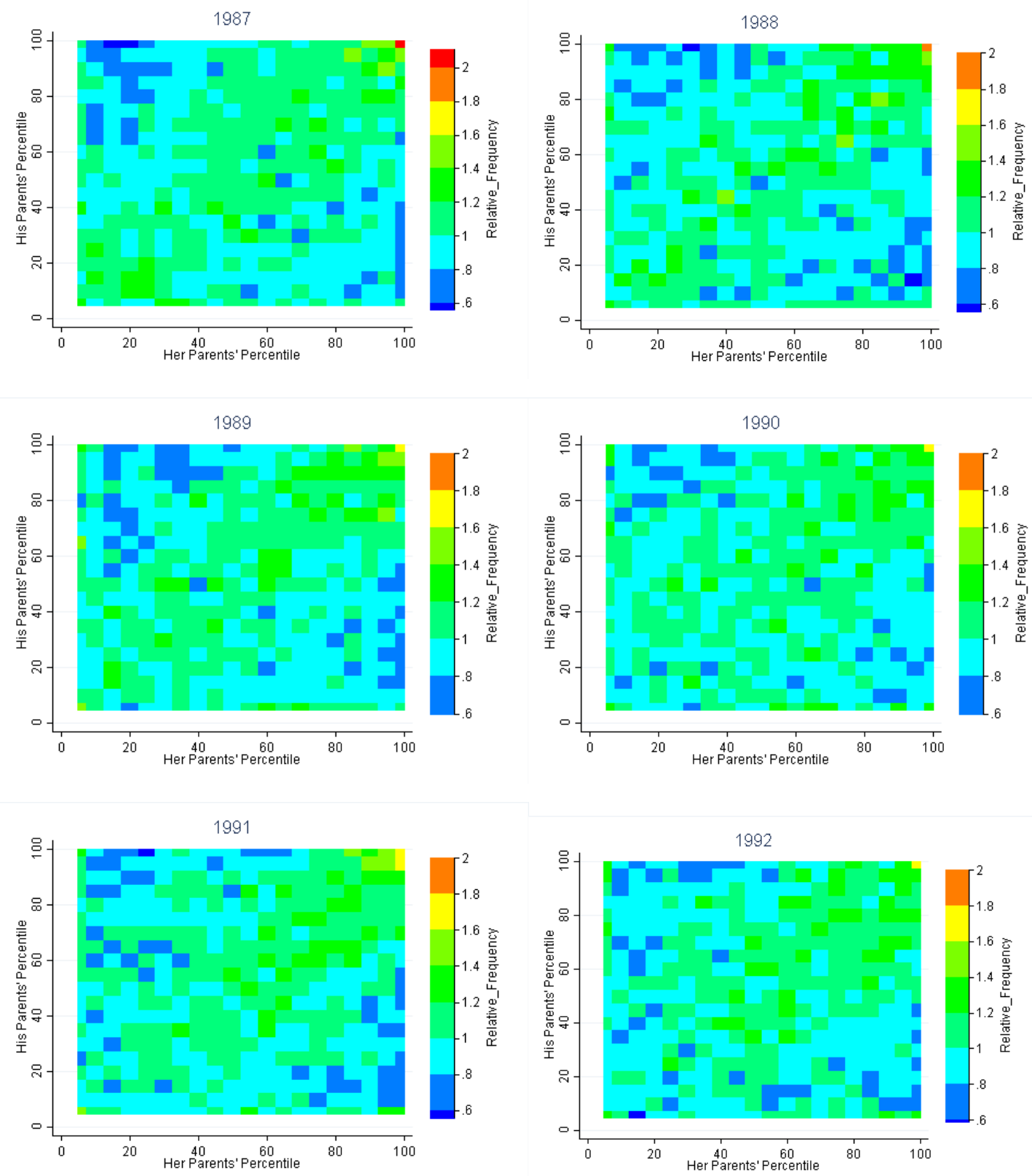
1993
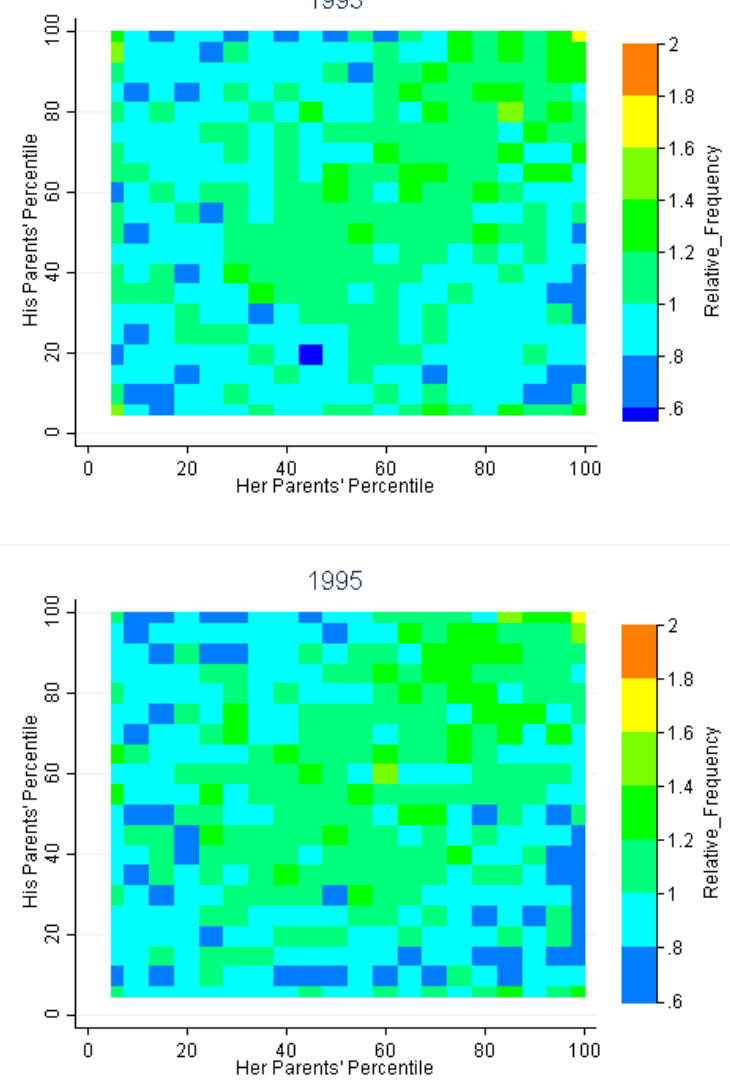

1997
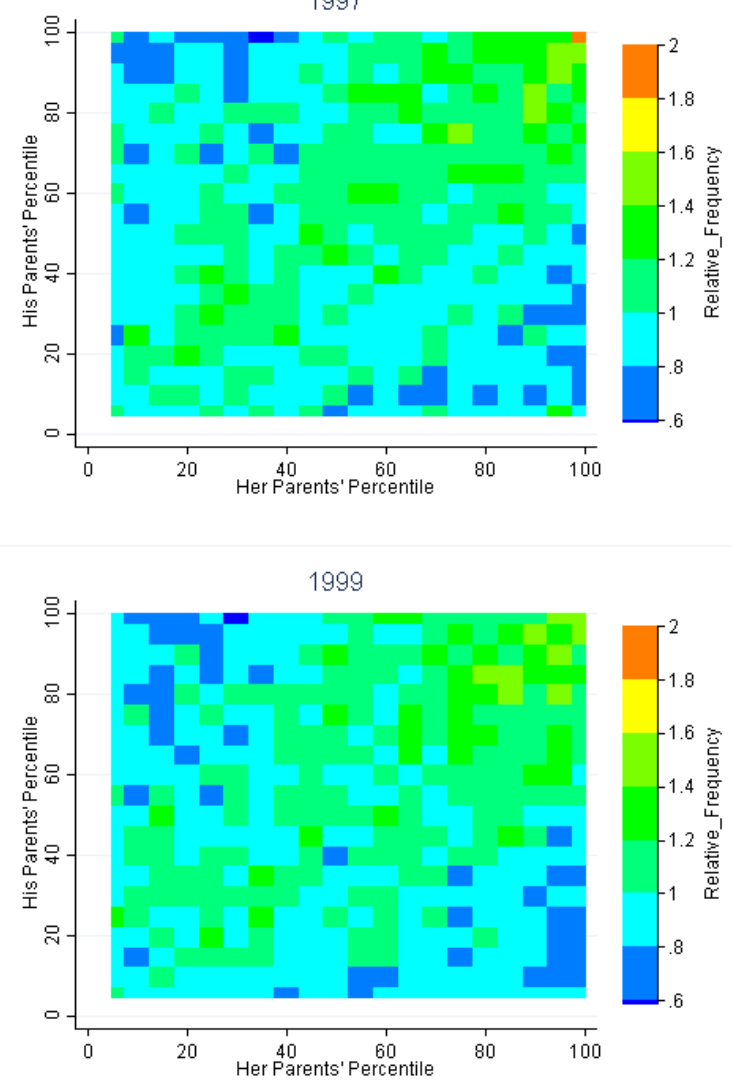
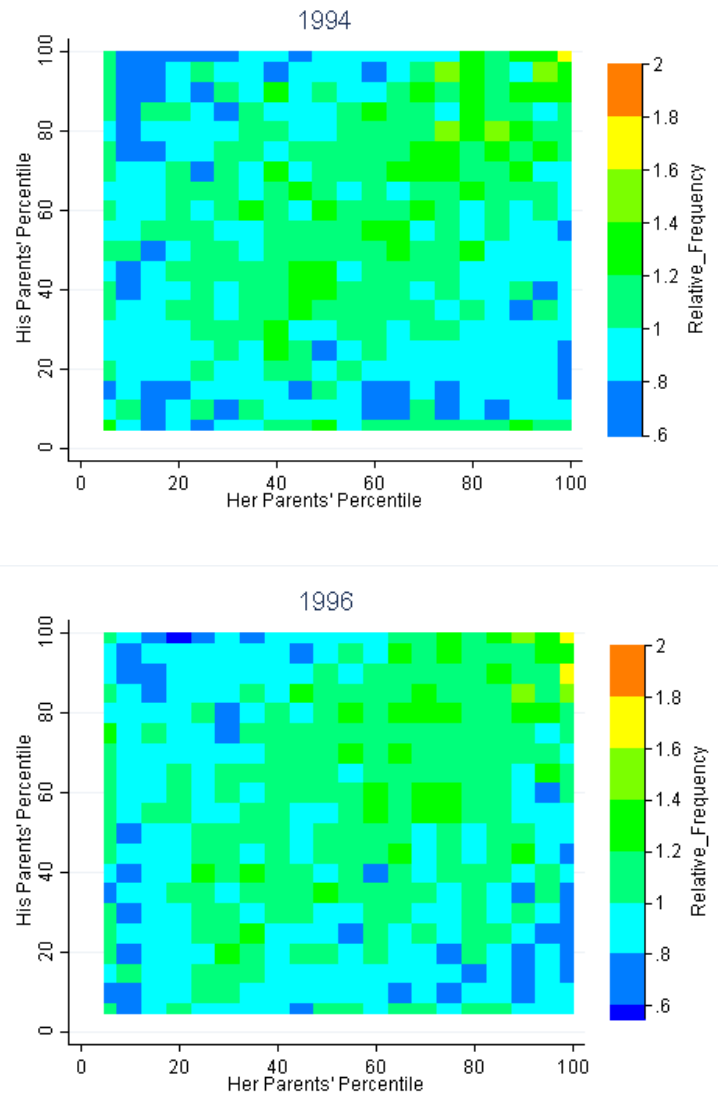

1998

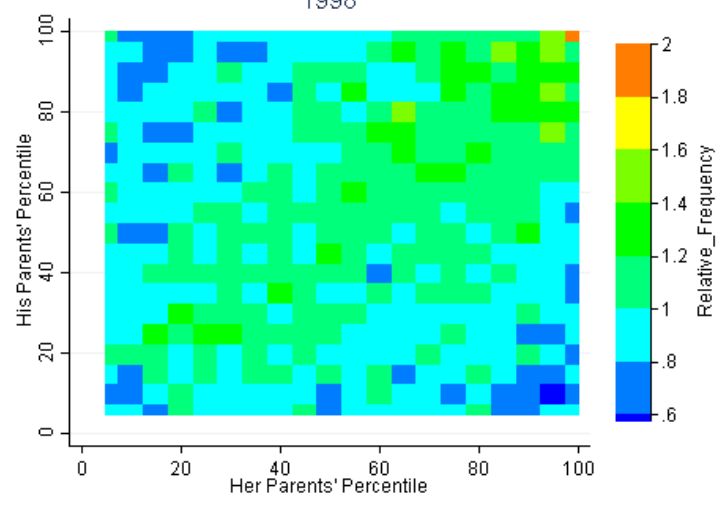

2000

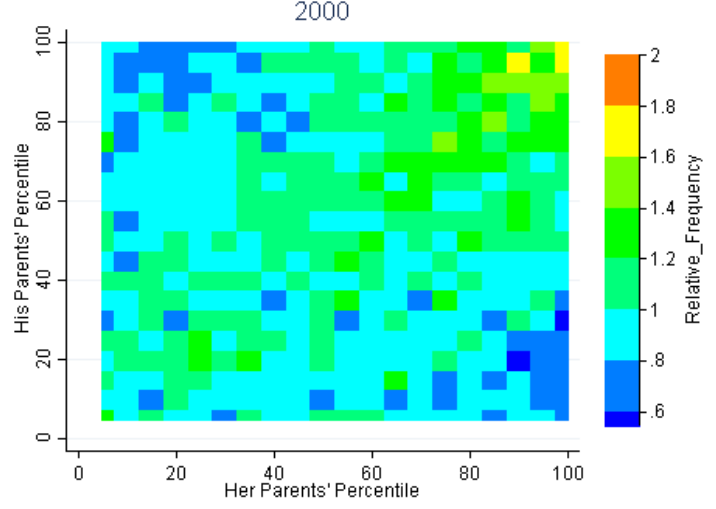



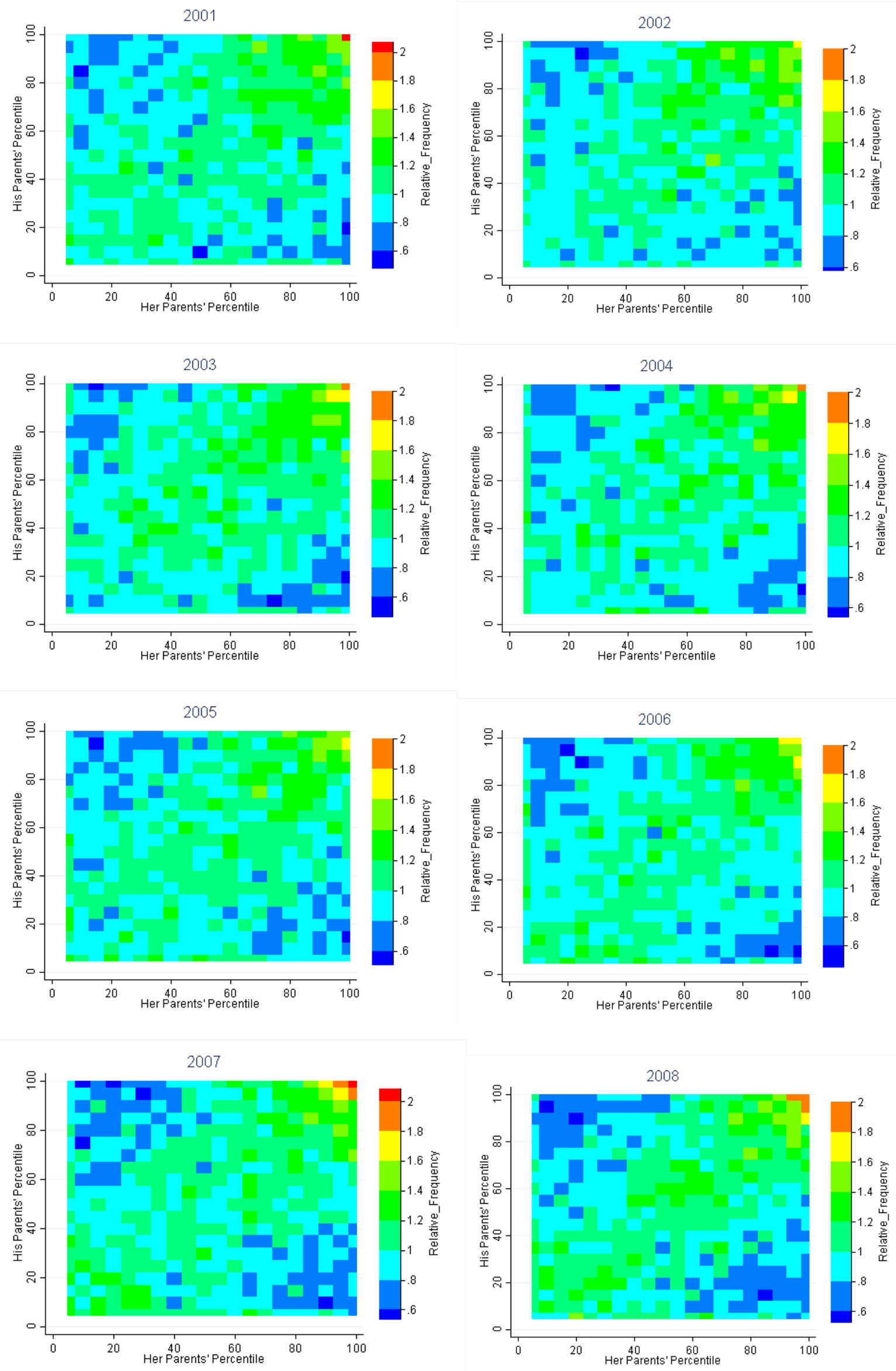

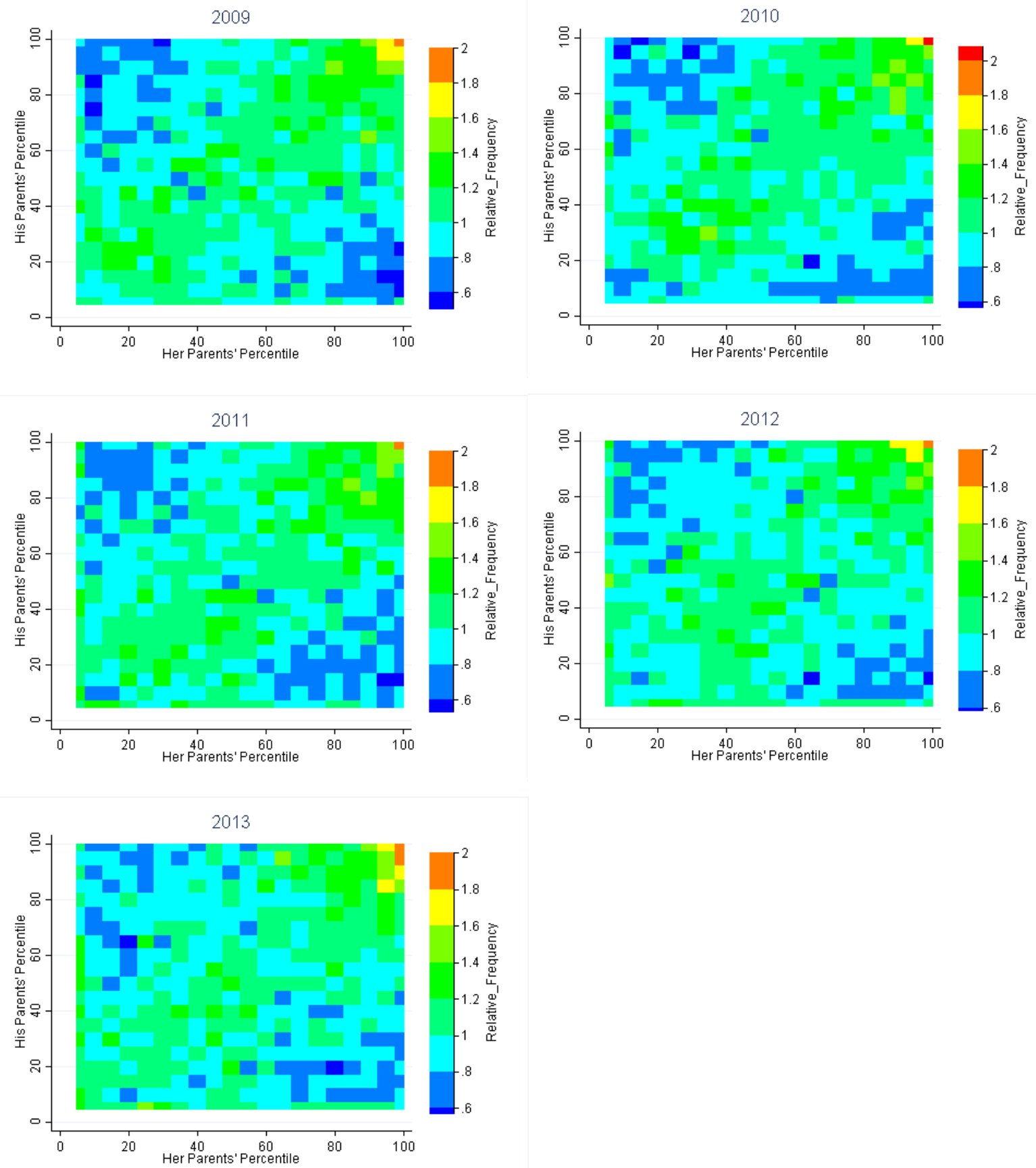

Note. Parental wealth percentile at union formation within union cohort. Frequency indicates relative frequency of combination of parental wealth percentiles; a value of one indicates relative frequency as expected based on random mating. 